\title{
Trends and time variability in the northern continental shelf of the western Mediterranean
}

\author{
M. Vargas-Yáñez, ${ }^{1}$ J. Salat, ${ }^{2}$ M. Luz Fernández de Puelles, ${ }^{3}$ J. L. López-Jurado, ${ }^{3}$ \\ J. Pascual, ${ }^{2}$ Teodoro Ramírez, ${ }^{1}$ Dolores Cortés, ${ }^{1}$ and Ignacio Franco ${ }^{4}$ \\ Received 9 November 2004; revised 7 June 2005; accepted 25 July 2005; published 18 October 2005.
}

[1] Different works appearing during the last decade show that the western Mediterranean has suffered a temperature and salinity increase during the 20th century. Most of these works analyze long-term trends in Levantine Intermediate Water (LIW) and Western Mediterranean Deep Water (WMDW); those dealing with changes in shallow and coastal waters are very scarce. It is still an open question whether these changes are due to meteorological factors occurring in the western Mediterranean or if they are caused by the salinity increase of the water masses contributing to deep water formation. In this work we analyze the data obtained in the last decade of the 20th century (and longer time series in some cases) within the frame of six projects aimed at the systematic collection of hydrographic data at fixed stations in the northern sector of the western Mediterranean (mainly in coastal areas). We detect strong warming trends in those stations located in the continental shelf (and probably with no influence of the LIW). This result could indicate that changes observed in the WMDW cannot be explained only on the basis of changes imported from the eastern basin. Another striking result is that these trends are an order of magnitude higher than those reported for the rest of the century, indicating that the 1990s have been an exceptionally warm decade. On the other hand, time series affected by the LIW show a salinity increase, and in some cases this is not accompanied by the corresponding temperature increment, indicating that the LIW salinity increase could also be a factor to be taken into account.

Citation: Vargas-Yáñez, M., J. Salat, M. Luz Fernández de Puelles, J. L. López-Jurado, J. Pascual, T. Ramírez, D. Cortés, andI. Franco (2005), Trends and time variability in the northern continental shelf of the western Mediterranean, J. Geophys. Res., 110, C10019, doi:10.1029/2004JC002799.

\section{Introduction}

[2] During the last decades there has been an increasing interest in the study of the Earth climate and its variability and in particular in the study of a possible global change due to the emission of greenhouse effect gases. According to the Intergovernmental Panel on Climatic Change [Intergovernmental Panel on Climate Change, 2001], the Earth temperature has an increase of $0.4^{\circ}-0.8^{\circ} \mathrm{C}$ since the end of the 19th century. The oceans seem to play an important role in this process as the increase in the heat content of the oceans has been an order of magnitude higher than the increase in heat content of the other components of the climate system: atmosphere and criosphere [Levitus et al., 2001].

\footnotetext{
${ }^{1}$ Instituto Español de Oceanografía, Centro Oceanográfico de Málaga, Málaga, Spain.

${ }^{2}$ Institut de Ciencies del Mar, CSIC, Barcelona, Spain.

${ }^{3}$ Instituto Español de Oceanografía, Centro Oceanográfico de Baleares, Palma de Mallorca, Spain.

${ }^{4}$ Instituto Español de Oceanografía, Centro Oceanográfico de Murcia, Murcia, Spain.

Copyright 2005 by the American Geophysical Union. 0148-0227/05/2004JC002799
}

[3] The Mediterranean Sea is one of the geographical areas where important changes have been well documented for the last years. It has also been recognized as an ideal test bed for climatic studies [CIESM Initiative Group, 2002]. It could be specially sensitive to atmospheric forcing and anthropogenic influence due to its location between continents and its reduced dimensions. During the late 1980s and early 1990s, there was a dramatic change in the thermohaline properties and circulation of the eastern Mediterranean. This has been known as the Eastern Mediterranean Transient (EMT) [see CIESM, 2000; Roether et al., 1996; Klein et al., 1999; Lascaratos et al., 1999; Theocaris et al., 1999]. The deep water formation area was shifted from the Adriatic to the Egean. There were changes in the thermohaline properties of the deep and intermediate water masses and in the circulation of the Ionian Sea [Pinardi et al., 1997]. Numerical simulations indicate that these changes could be caused by variations in the meteorological forcing [Lascaratos et al., 1999].

[4] There have been long-term changes too. Rholing and Bryden [1992] showed that the Levantine Intermediate Water (LIW) core salinity (salinity maximum) had increased in the Ionian basin at a rate of $0.002 \mathrm{yr}^{-1}$ from the beginning of the 20th century to 1992 and at a rate of $0.005 \mathrm{yr}^{-1}$ from 1955 to 1992. Tsimplis and Baker [2000] 
estimated significant trends for the potential temperature at

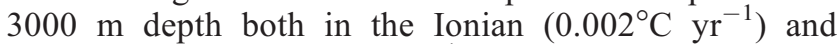
Levantine basins $\left(0.001^{\circ} \mathrm{C} \mathrm{yr}^{-1}\right)$. These trends correspond to the second part of the 20th century. They also reported positive trends for the salinity at the same depth and in both basins, but none of them were statistically significant.

[5] Concerning the western basin, it has been observed an increase of the temperature and salinity of the Western Mediterranean Deep Water (WMDW) and the LIW. According to Béthoux et al. [1990, 1998] and Béthoux and Gentili [1996], WMDW has increased its temperature and salinity at a rate of $0.0035^{\circ} \mathrm{C} \mathrm{yr}^{-1}, 0.001 \mathrm{yr}^{-1}$ in the period 1957-1997. The increase of temperature and salinity of the LIW in the same period has been $0.0068^{\circ} \mathrm{C} \mathrm{yr}^{-1}$ and $0.0018 \mathrm{yr}^{-1}$ respectively. These results are in agreement with those of Leaman and Schott [1991] who reported an increment of $0.026^{\circ} \mathrm{C}$ per decade for the WMDW. WMDW and LIW have increased its temperature and salinity in the western basin, with an acceleration of these trends in the second part of the 20th century. We have to point out that many of these works analyze data extending to the early 1990s [Leaman and Schott, 1991; Rholing and Bryden, 1992] but the 1990s could have been an exceptionally warm decade with an increment of an order of magnitude in the temperature warming trends. Fuda et al. [2002] reported a trend of $0.016^{\circ} \mathrm{C} \mathrm{yr}^{-1}$ in the deep water of the Tyrrhenian Sea during the 1990s. Vargas-Yáñez et al. [2002] and Salat and Pascual [2002] also reported a warming trend around $0.02^{\circ} \mathrm{C} \mathrm{yr}^{-1}$ in the continental shelf waters of the NW Mediterranean and the Alboran Sea in the last part of the 20th century.

[6] There is some controversy about the origin of these trends. According to Leaman and Schott [1991] and Rholing and Bryden [1992], these changes could be linked to the damming of the Nile and the main rivers that drain into the Black Sea. The reduction of the fresh water supply in the Levantine basin would have produced the increase of salinity of the LIW. This water mass is exported to the western basin and plays an important role in the preconditioning process previous to the WMDW formation in the northwest Mediterranean. Saltier waters would reach the WMDW density with higher temperature. A second hypothesis is that the warming in the western Mediterranean is due to a change in the atmospheric conditions in the areas where this water mass is formed, being these changes related to the global change. A third hypothesis considers that the WMDW warming is due to the salinity increase of the surface layer in the western Mediterranean [Krahmann and Schott, 1998; Send et al., 1999].

[7] Most of previous works analyze time series obtained from different surveys irregularly distributed in time and space. Trends are estimated fitting a straight line by least squares and considering the residuals as statistically independent. The irregular distribution of the data and the large gaps present in these series do not allow to check the hypothesis of statistical independence and the normality of the residuals. Most of these works do not address the trend detection in shallow waters where the noise variance is very large and time series are affected by intense seasonal cycles. A systematic and periodic sampling is needed to remove these cycles. Nevertheless this is an important question as coastal waters are not affected by LIW and the detection of warming trends in these waters could be considered as an indication of the local character of the western Mediterranean warming.

[8] The goal of this work is to study in a comparative and comprehensive way most of the systematic sampling programs in the northern shelf of the western Mediterranean, focusing on the upper $200 \mathrm{~m}$ layer. The systematic and routine character of the sampling will allow us to remove the seasonal signal from the time series and to check the hypothesis usually applied in classical statistical analysis, that is, statistical independence and normality of the residuals. We will analyze the existence of significant warming trends in the different areas covered by our data set.

[9] In section 2 we present the data set and we characterize the different areas analyzed from an oceanographic point of view. In section 3 we describe the statistical tools used in the analysis. Results are in section 4 and we finalize with a summary and conclusions section.

\section{Data}

[10] We analyze data from six projects with periodic or quasi-periodic surveys in the western Mediterranean. These are the ECOMÁLAGA, ECOMURCIA, ECOBALEARES (EMA, EMU, EBA hereafter), and CIRBAL projects, supported by Instituto Español de Oceanografía (IEO), L'Estartit station (LE), supported by Institut de Ciencies del Mar (ICM) and DYFAMED Station (DYF), supported by Observatoire oceanologique de Villefranche-sur-mer.

[11] EMA, EMU and EBA are three multidisciplinary projects aimed at the monitoring of the environmental conditions within the continental shelf waters of the Spanish Mediterranean. The sampling in the three projects includes CTD casts with a SeaBird probe, periodically calibrated by SeaBird technical service.

[12] EMA is made of nine stations distributed along three onshore-offshore transects extending from Cape Pino, Málaga and Vélez (Figure 1b). Here we analyze temperature and salinity time series from the most offshore stations located around the shelf break (bottom depths 500, 200 and $300 \mathrm{~m}$ for C. Pino, Málaga and Vélez, respectively). We analyze time series from 5 to $200 \mathrm{db}$ at a $5 \mathrm{db}$ interval. The sampling is 3 monthly and started in October 1992. The time series analyzed extend to October 2001. EMU is made of nine stations, but most of them are very shallow. For this reason we selected the stations EMU6, within the continental shelf and a bottom depth of $100 \mathrm{~m}$ and EMU9 at the initial part of the slope (bottom depth around $500 \mathrm{~m}$, see Figure 1c). The data set corresponding to this project is not yet freely available and information to which we had access is not organized systematically. This made untreatable the joint analysis of the whole water column as in the EMA case. Main trends in the Alboran Sea were detected at $200 \mathrm{db}$ [Vargas-Yáñez et al., 2002]. For comparison and for trying to determine if this previous result was a local or regional (basin-wide) effect, we selected the temperature and salinity time series at 200 and $100 \mathrm{db}$ in EMU9 station. In the case of EMU6, though the bottom depth is $100 \mathrm{~m}$, the CTD was not always lowered to this maximum depth due to small positioning errors, so we selected $90 \mathrm{db}$ 

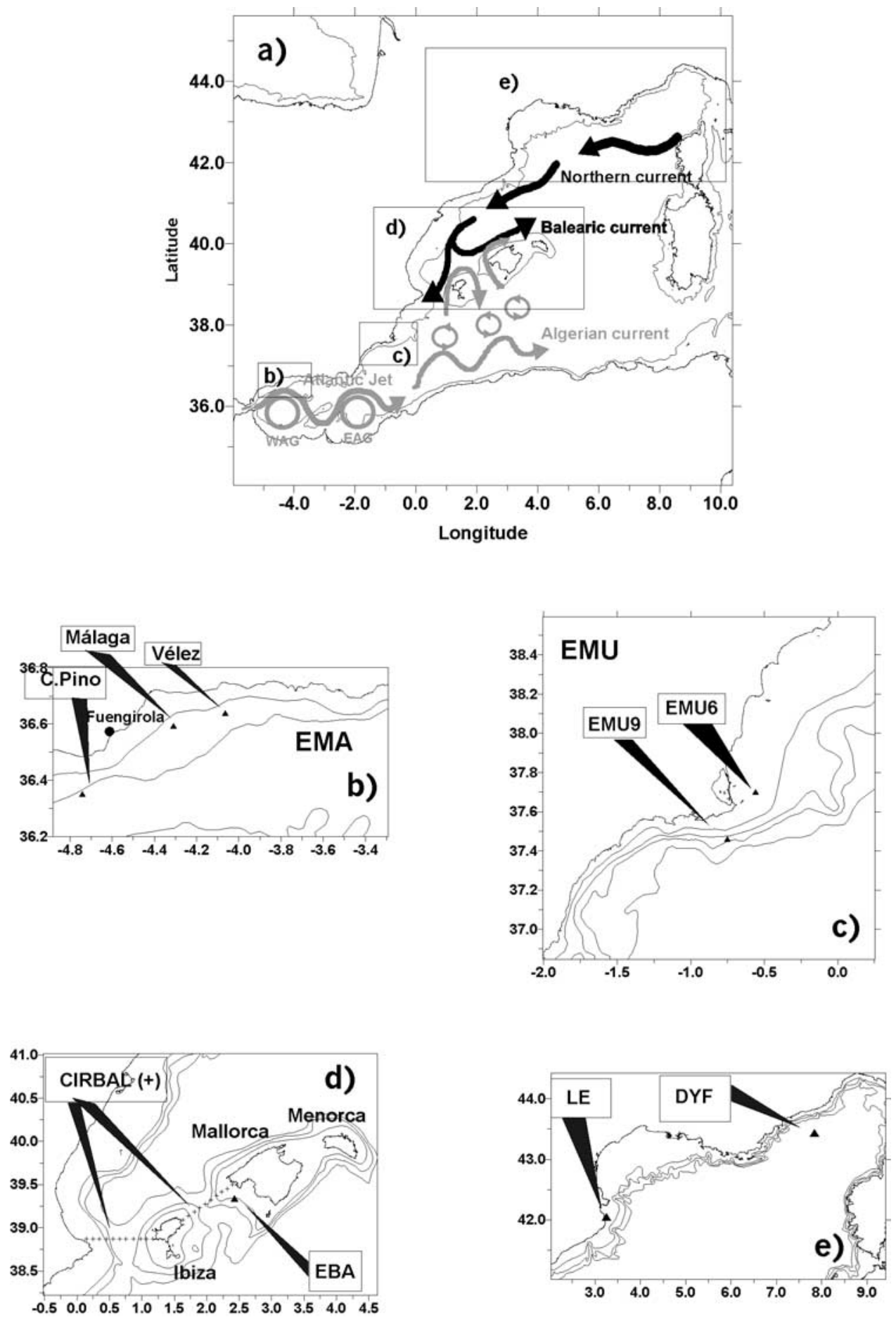

Figure 1. (a) Map of the study area. The different projects analyzed correspond to four different geographical areas that are labeled as follows: (b) EMA area (triangles are the positions of the three offshore stations analyzed (C. Pino, Málaga, and Vélez in the text)); (c) EMU area (positions of EMU6 and EMU9 stations are indicated); (d) EBA area (the triangle is the most offshore station from EBA project, and crosses are the sections occupied in all the CIRBAL cruises); and (e) positions for LE and DYF stations. In Figures $1 \mathrm{~b}-1 \mathrm{e}$ the 200, 500, 1000, and $2000 \mathrm{~m}$ isobaths are included. Principal characteristics of the circulation of the region are also shown.

(to avoid excessive gaps) to construct the time series of temperature and salinity. This project started in June 1996, the sampling is 3 monthly and the time series analyzed extend to November 2001. EBA is made of a single onshore- offshore transect located to the south of Mallorca Island. Here we analyze time series from the most offshore station on the shelf break (bottom depth 200 m, see Figure 1d). The sampling was monthly from January 1994 to December 
1999 and 3 monthly for the years 2000 and 2001. Since 1994 to 1997 , temperature and salinity measurements were taken with oceanographic bottles at discrete depths $(0,50,75,100$ and $200 \mathrm{~m}$ ). Since 1997, a CTD probe was used. Thermometer and CTD measurements were intercalibrated to guarantee the homogeneity of the time series. We analyze in this work temperature and salinity time series at the initial discrete sampling depths.

[13] LE station is located on the continental shelf of the Catalonian Sea (Figure 1e) over a bottom depth of $85 \mathrm{~m}$. The sampling is discrete, and consists of temperature measurements at $0,20,50$ and $80 \mathrm{~m}$. These time series extend from 1974 to 2001. The sampling is weekly. Data have been averaged to get monthly time series.

[14] DYF station is in the central part of the Ligurian Sea and is visited on a monthly basis by the Observatoire de Oceanologique de Villefranche-sur-mer (Figure 1e). This location is not on the continental shelf, and we have to remark that the upper layer $(0-200 \mathrm{~m})$ at the open sea is very likely to have a different behavior to that of coastal or shelf stations. We included temperature and salinity time series at $0,20,50$ and $80 \mathrm{~m}$ for comparison with LE station. According to the circulation scheme in Figure 1a, there could be some connections between the oceanographic conditions in DYF, LE and EBA, being the northern current the link between these three locations. Nevertheless we admit that this cannot be stated a priori, as the northern current flows along the slope and LE is in the inner part of the continental shelf. We also include series at $200 \mathrm{~m}$ to check the similarities/ differences of this depth level at the open Sea with similar depths at the shelf break of the other areas studied in this work.

[15] CIRBAL project is devoted to study the circulation within the Baleric Sea. This project started in 1996. One survey was carried out in spring 1996, 1997, 1998, 1999 to study mainly the evolution of the Western Intermediate Water (WIW) through the Balearic Channels. In the year 2000, two surveys were carried out in late summer and autumn and four more surveys in 2001. The number of stations could change from a survey to another. Here we analyze two transects crossing Mallorca and Ibiza Channels which were occupied in all the cruises (Figure 1d).

[16] Additionally to the long-term projects described above, we used data from two oceanographic cruises carried out in the Alboran Sea in May 1998 and November 1999. The May 1998 cruise was carried out in the frame of the European Project MATER. We analyze 35 TS profiles within a box extending from $4^{\circ}$ to $4.5^{\circ} \mathrm{W}$ and from $36^{\circ}$ to $36.5^{\circ} \mathrm{N}$. The November 1999 cruise was supported by IEO and consisted of four repetitions of an hydrographic section made of 6 stations extending along $4.5^{\circ} \mathrm{W}$ and from $36^{\circ}$ to $36.5^{\circ} \mathrm{N}$. These data are used for the propose of discussion about changes in the TS properties of the LIW within the Alboran Sea.

[17] To get information about the atmospheric conditions and possible teleconnections, we also analyzed monthly time series of sea surface temperature (SST, from 1984 to 2001) and air temperature (1992-2001) in Fuengirola beach (Figure 1b) and monthly time series of wind strength and air temperature (1971-2001) in the LE meteorological station.
Monthly values of air temperature and SST in the western Mediterranean were obtained from the Web site of the National Centre for Environmental Prediction (NCEP) reanalysis project (http://www.cdc.noaa.gov). The time series used are the mean value for a rectangle extending from $2^{\circ} \mathrm{W}$ to $10^{\circ} \mathrm{E}$ and from $35^{\circ}$ to $44^{\circ} \mathrm{N}$. We obtained monthly and winter (January-February-March) NAO index from the Climatic Research Unit of the University of East Anglia (http://www.cru.uea.ac.uk/tiempo/floor2/data/nao.htm) [Jones et al., 1997]. We also used data from MEDATLAS [IFREMER, 1997] to get the climatological temperature and salinity profiles in those locations where our own data set was discrete. All temperature and salinity time series are expressed in Celsius degrees and the practical salinity scale (PSS78 [Lewis, 1980]).

\subsection{Oceanographic Background of the Sampling Area}

[18] The study area covers a large part of the northern continental shelf of the western Mediterranean. According to the geographical location of the sampling stations, they are supposed to have some common features as well as important differences caused by the circulation of the different water masses (see Millot [1999] for an exhaustive description). The general circulation of the upper layer in this basin (100-200 m thickness) is dominated by the inflow of low-salinity Atlantic Water (AW) through the Strait of Gibraltar. This water mass gets into the Alboran Sea forming a swift jet which forms two anticyclonic meanders before it progresses through the Algerian basin forming the Algerian current. When this current reaches the Strait of Sicily, it is divided in two branches. The first one gets into the eastern Mediterranean, and the second one turns to the north getting into the Tyrrhenian Sea. The AW continues to the north and to the west completing a cyclonic circuit along the Ligurian, Catalonian and Balearic seas (Figure 1a). The northern part of this circuit is known as the northern current. Below the AW it can be found the LIW, characterized by a temperature and salinity maximum, while the deepest part of the western basin is occupied by the WMDW. During severe winters a modal water mass can be formed in the Catalonian shelf. This is the Western Intermediate Water (WIW) which is located below the AW and above the LIW. The temperature and salinity of this water mass ranges between $12.5^{\circ}-13^{\circ} \mathrm{C}$ and $38.1-38.3$ [Salat and Cruzado, 1981; Salat and Font, 1987]. The WIW flows to the south through the Ibiza Channel with the northern current and can be found in the Alboran Sea and even in the Strait of Gibraltar [Katz, 1972; Cano and Gil, 1984; Gascard and Richez, 1985].

[19] The first area studied in this work is within the Alboran Sea. The Atlantic Jet (AJ) flows eastward to the south of Cape Pino and then turns to the southeast [Parrilla and Kinder, 1987]. Owing to the shape of the shore line, Cape Pino is directly influenced by this current while Málaga and Vélez are supposed to have a lower influence. Vargas-Yáñez et al. [2005] show that salinity is lower in Cape Pino than in Málaga and Vélez and the interface separating AW from Mediterranean waters is also deeper in Cape Pino than in the other two stations. To get the typical temperature and salinity profile for this area we averaged all the available profiles from EMA 

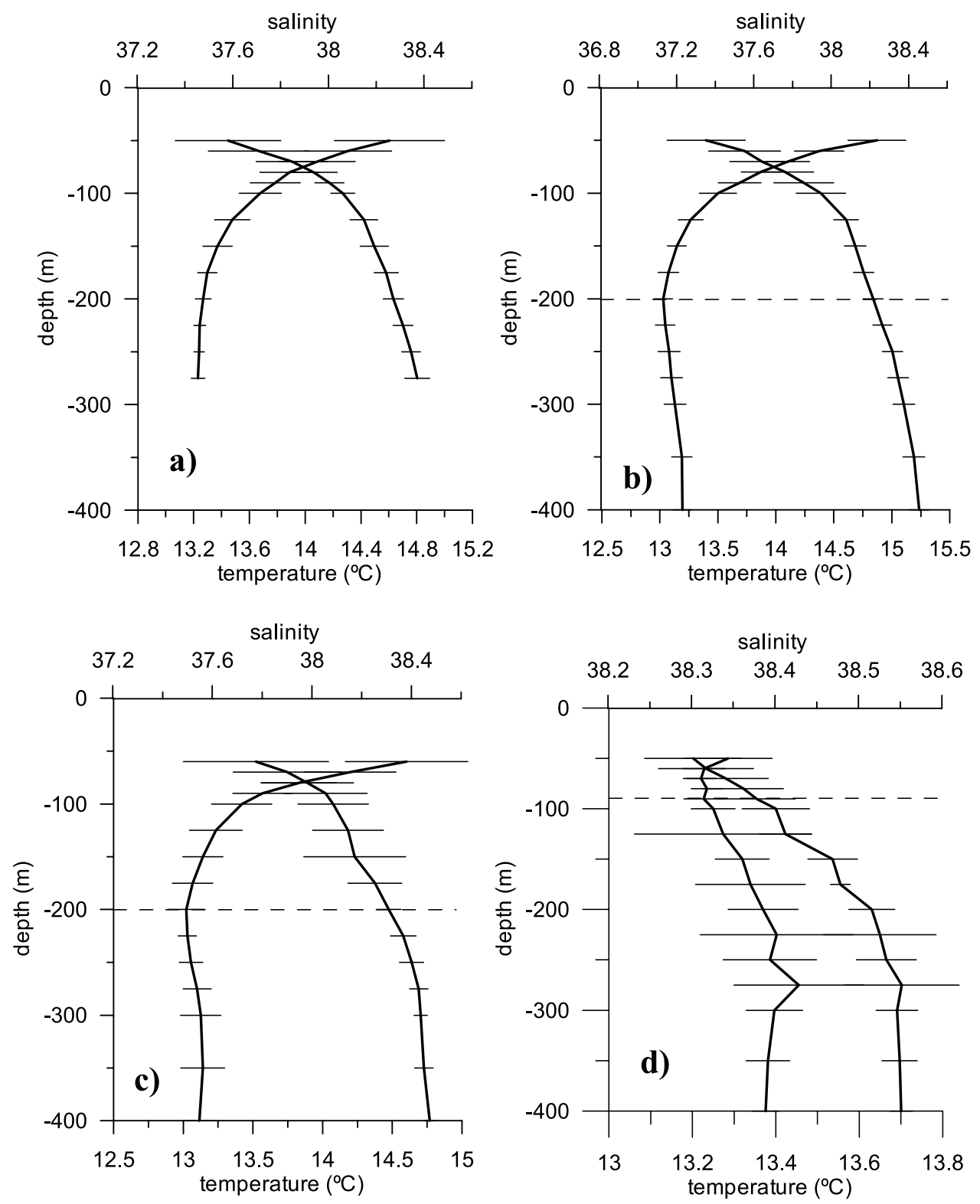

Figure 2. Mean temperature and salinity profiles for the summer season in the areas of (a) EMA, (b) EMU, (c) EBA, and (d) DYF. In the case of EMA and DYF we have used our own data set, while in the case of EBA and EMU we have obtained the mean profiles form MEDATLAS database. Horizontal solid lines are the $95 \%$ confidence intervals. Dashed horizontal lines indicate the beginning of the LIW influence. The upper $50 \mathrm{~m}$ has been omitted to enhance variations within the intermediate layer.

corresponding to summer. The reason for limiting this analysis to summer is for comparison with the other areas. In some of them, the sampling is discrete and to get the climatological profiles we used MEDATLAS data. In most of the cases only in summer there were enough profiles available to get the mean values. Figure 2 a shows these profiles with the $95 \%$ confidence intervals at selected levels. As already stated, the LIW is characterized by a maximum of temperature and salinity. In Figure $2 \mathrm{a}$ can be seen that salinity increases continuously with depth, corresponding the maximum value to the maximum depth sampled (38.37, far from the LIW values). Temperature decreases with depth along the whole profile. Although the temperature and salinity maximum characterize the core of the LIW, its influence can be felt in shallower waters far from the core. The criterion used in this work is that LIW influence is considered when temperature increases with depth. According to this criterion there is no LIW influence in the EMA continental shelf.

[20] The second area is EMU (Figure 1c). This is located to the north of the Almeria-Oran front [Tintoré et al., 1988] which separates the fresh AW to the south from the saltier and denser waters to the north. This area receives the severely modified AW advected by the northern current through the Ibiza channel and could also be easily affected by WIW. As already explained in section 2, we had no access to the whole EMU data set. For this reason and in order to determine the typical TS 
conditions in this area, we used all the profiles available in MEDATLAS in the area surrounding EMU9 and corresponding to the summer season. The maxima of temperature and salinity are $13.20^{\circ} \mathrm{C}$ and 38.45 respectively and were found at the maximum depth sampled $(400 \mathrm{~m})$. Though the core of LIW is not reached at this mean profile, the influence of LIW starts at $200 \mathrm{~m}$ according to the change in the sign of the derivative of temperature with depth.

[21] The following sampling area to the north are the Balearic Channels. The northern current flows along the Spanish slope advecting AW in its upper layer, then WIW, between 200 and $400 \mathrm{~m}$, and then LIW and WMDW. The northern current flows mainly through the Ibiza Channel, though a branch of it is deflected to the east forming the Balearic current and the Balearic front to the north of the Islands. Pinot et al. [2002] have evidenced that the amount of WIW formed in late winter suffers a strong interannual variability, making this water mass suitable as indicator of climate variability. We analyze the time series of temperature and salinity in the most offshore station of EBA (Figure 1d), which is on the shelf break to the south of Mallorca Island. As the available data set for the years 1994, 1995, 1996 and 1997 was discrete, we have got from MEDATLAS all the available TS summer profiles for the area surrounding EBA station. Figure $2 \mathrm{c}$ shows the mean temperature and salinity profile. We see that temperature starts increasing just below $200 \mathrm{~m}$, indicating the mixing with LIW. The maximum of temperature is $13.14^{\circ} \mathrm{C}$ and is found at $375 \mathrm{~m}$, the maximum of salinity (38.47) is at the maximum depth, indicating that the LIW core is not reached in this mean profile.

[22] Finally we consider the northernmost area of our work which encloses the Ligurian Sea and the Catalonian continental shelf (Figures 1a and 1e). The southernmost of the two stations located in this area is LE station. This is the shallowest station analyzed in this work (over a bottom depth of $85 \mathrm{~m}$ ). Taking into account the depth of the LIW in the areas to the north and to the south of LE, we can accept that this station is very far away from the influence of the LIW. DYF station is not on the continental shelf. Here we analyze the upper $200 \mathrm{~m}$. The objective of the inclusion of DYF station is to compare the behavior of the upper $200 \mathrm{~m}$ in coastal waters and in the open sea. Figure $2 d$ shows the mean summer TS profiles obtained from the DYF data set. salinity increases directly from the surface to the maximum (38.55) at $275 \mathrm{~m}$. This is coincident with the maximum of temperature $\left(13.45^{\circ} \mathrm{C}\right)$. Temperature starts increasing from $90 \mathrm{~m}$, indicating a strong influence of the LIW in the upper layers.

[23] We can summarize that there are two areas, EMA and LE, where no LIW influence is found, (according to the criterion that temperature decreases continuously with depth). There are two more areas, EMU and EBA, where the influence of LIW is not observed in the upper $200 \mathrm{~m}$, but it starts just below this depth. Interannual changes in the thickness or TS characteristics of this water mass, could have some influence in the layer just above. Finally, we identify the area sampled in DYF station as highly influenced by the LIW. The discussion of trends and time variability in the following sections will take into account the different character of these areas.

\section{Statistical Analysis}

[24] Let us consider a certain variable $\psi$ (temperature, salinity, density, etc.). This variable depends on the position $\mathbf{r}$ and time $t$. We consider that $\psi$ is made of a deterministic part and a random part: $\psi(\mathbf{r}, t)=f(\mathbf{r}, t)+\varepsilon(\mathbf{r}, t)$. Variable $f$ represents the expected value of the variable that can depend both on the space (nonhomogeneity) and on the time (nonstationarity). A clear case of non stationary is the existence of a seasonal cycle. In such a case, $f$ will be a periodic function with a 1 year period. Variable $\varepsilon$ is a random variable with zero mean, and represents the fluctuations around the expected value. These fluctuations can be correlated in time; $\gamma(u)=\langle\varepsilon(\mathbf{r}, t) \varepsilon(\mathbf{r}, t+u)\rangle$ is the covariance function for a fixed position and a time lag $u$. Brackets denote expectation. The covariance function will tend to zero as $u$ tends to infinity. In practice, we can consider that $\gamma$ is zero for $u>u_{0}$, and $u_{0}$ defines the characteristic timescale of the phenomena causing the deviations or residuals expressed by $\varepsilon$. At the same time, any variable at different positions can also covariate: $\gamma(\mathbf{I})=$ $\langle\varepsilon(\mathbf{r}, t) \varepsilon(\mathbf{r}+\mathbf{l}, t)\rangle$ will be the covariance function and it will be zero for $\mathbf{l}>\mathbf{I}_{0}, \mathbf{l}_{0}$ being a characteristic length scale [see, e.g., Jenkins and Watts, 1968; Thiebaux and Pedder, 1987; Box et al., 1994].

[25] There is a wide set of phenomena causing the deviations around the expected values. The time and length scales associated to them will vary within a large range. Some of them can simply be error measurements or can have timescales of the order of hours (internal waves). In other cases, they will have timescales of the order of weeks, months or even years. In general, short-timescale phenomena will have a local character, while long-timescale ones will be spatially coherent over large areas. Some examples of these large-scale phenomena are shifts in the NAO index phase [Hurrell, 1995], interpentadal variability in the North Atlantic water masses [Levitus, 1989], or in the particular case of the Mediterranean, the Eastern Mediterranean Transient, affecting to large areas of the eastern Mediterranean [Roether et al., 1996; Klein et al., 1999; Lascaratos et al., 1999; Theocaris et al., 1999] or the changes in the Balearic Channels circulation [Pinot et al., 2002].

[26] In practice, we have a discrete set of observations $\psi\left(\mathbf{r}_{\alpha}, t_{i}\right)$ at certain locations $\mathbf{r}_{\alpha}, \alpha=1, \ldots M$, and at times $t_{i}, i=1, \ldots n_{\alpha}$; that is, we have $M$ time series, each one with $n_{\alpha}$ observations. If the time step of the series is longer than the timescale of the phenomena studied, then, successive observations of $\varepsilon$ will be statistically independent, and $\varepsilon$ will be considered simply as a noise. Contrary to this, if the timescale is longer than the time step, $\varepsilon$ will be serially autocorrelated.

[27] We consider that the deterministic part in our time series is made of a seasonal cycle and a possible long-term trend, so we adopt the following model:

$$
\psi(\mathbf{r}, t)=a(\mathbf{r})+b(\mathbf{r}) t+f(\mathbf{r}, t)+\varepsilon(\mathbf{r}, t),
$$

where $a, b$, express the possible existence of a linear trend, $f$ is a periodic function with a 1 year period, and $\varepsilon$ is the 
random part, deviations or residuals. The usual approach to estimate the linear trend is to remove the seasonal cycle and then to fit a straight line by least squares and then to get the confidence intervals for the slope of the fit:

$$
\begin{gathered}
\hat{b}=\frac{\sum_{i=1}^{n} y_{i}\left(t_{i}-\bar{t}\right)}{\sum_{i=1}^{n}\left(t_{i}-\bar{t}\right)^{2}} \\
d= \pm \frac{\hat{s}}{\sqrt{\sum_{i=1}^{n}\left(t_{i}-\bar{t}\right)^{2}}} T_{n-2}(1-\alpha / 2),
\end{gathered}
$$

where $\hat{b}$ is the estimation of the slope, $d$ is the confidence interval at the $\alpha$ level of significance, $\hat{s}$ is the estimation of the standard deviation, and $T_{n-2}$ is the inverse of the $t$ student cumulative probability function with $n-2$ degrees of freedom. We used two procedures to remove the seasonal cycle and obtain the linear trend. The first one was to get the averaged seasonal cycle, that is the mean value for each month of the year in the case of the monthly time series, and the mean value for each season of the year when the sampling is 3 monthly. Then we subtracted this seasonal cycle to the time series and finally we fitted a straight line to it. The second procedure was to fit a function of the form $a+b t+f(t)$ as indicated in (1), being $f(t)$ a combination of harmonics. The number of harmonics was the maximum allowed by the sampling time step. Results did not differ substantially using any of the two procedures. Whatever is the method used, most of the works dealing with trend detection in the Mediterranean assume that the residuals are normally distributed and statistically independent, two requirements for the validity of expression (3). Nevertheless these hypothesis are not checked. The use of routine sampling allows to address these statistical questions.

[28] For each time series, we obtained the time series of residuals or deviations around the mean (the random part) as: $\varepsilon_{i}=\Psi_{i}-a-b t_{i}-f_{i}$. As already mentioned, it is usually assumed that these residuals are normally distributed with zero mean and a certain standard deviation. If we divide each time series of residuals by its corresponding standard deviation we expect that it will follow the probability density distribution $(1 / \sqrt{2 \pi}) e^{-\left(\varepsilon^{2} / 2\right)}$. For each different project (EMA, EMU, EBA, LE and DYF) we grouped the standardized residuals in bins of size $\Delta \varepsilon$, and obtained the relative frequency for each bin, that is, the number of residuals within that bin divided by the number of observations. Results are shown in Figures $3 \mathrm{f}-3 \mathrm{j}$. The theoretical relative frequencies for a normal distribution would be
$(1 / \sqrt{2 \pi}) e^{-\left(\varepsilon^{2} / 2\right)} \Delta \varepsilon$ and has been included as a continuous line in Figures $3 \mathrm{f}-3 \mathrm{j}$. We performed Chi-squared tests to all the time series not allowing to reject the null hypothesis that the residuals were normally distributed. The second important question is the statistical independence of the residuals.

[29] For each time series we calculated the autocorrelation function for time lag $k$ as

$$
\rho(k)=\sum^{\varepsilon_{i} \varepsilon_{i+k}} / \sigma_{\varepsilon}^{2} .
$$

Figures $3 \mathrm{a}$ and $3 \mathrm{~b}$ show the autocorrelation coefficient for lag-1 as a function of the depth of the different time series analyzed. As these series are 3 monthly this means a 3 month delay. Accepting that the time series and the delayed time series are independent we include the $95 \%$ percentile of statistical significance. According to these figures, the correlation found is compatible with a white noise in most of the cases. Figure $3 \mathrm{c}$ is the same for the case of EBA. Triangles are the 1 month delay correlation coefficient. The corresponding $95 \%$ percentile is the lowest one. We see that the residuals are significantly correlated. We then considered the possibility of subsampling with a 2 month time step. Circles represent the new correlation coefficient and the percentile is the intermediate one. As could be expected the correlation is lower and not significant for 0 and $50 \mathrm{~m}$. Nevertheless it is still significant for 75,100 and $200 \mathrm{~m}$. Then we averaged all the values within each season of the year to have a 3 monthly time series. The new correlations are represented in Figure $3 \mathrm{c}$ by squares. It is interesting to note that the correlation is higher than for the subsampled time series, and this correlation is significant for 50, 75, 100 and $200 \mathrm{~m}$. Two explanations are possible. The first one is that the lag-1 correlation coefficients represented in Figure $3 \mathrm{c}$ are just an estimation from a finite set of data. This estimator is also a random variable, and considering the whole data or a subset of it can produce different values. Nevertheless we believe that it is more likely that there is some sort of long-term correlation that is obscured by high-frequency variability. The seasonal average would filter out this variability and correlation would arise. Figure $4 \mathrm{~d}$ shows the time series of seasonal averages in EBA temperature at $200 \mathrm{~m}$. The seasonal cycle has been subtracted and we have included the linear trend that should be considered as the expected value. For a white noise, values should be distributed randomly around the straight line. If the noise is colored and positively correlated, positive (negative) deviations are more likely to be followed by positive (negative) deviations producing a long-period oscillation pattern. Figure $4 \mathrm{~d}$ shows that temperature deviations from the linear fit tend to increase from 1997 , being most of the values for 1998 and 1999 over the

Figure 3. Lag-1 autocorrelation function versus depth for (a) EMA, (b) EMU, (c) EBA, (d) LE, and (e) DYF. In all the cases the squares indicate 3 monthly sampling or seasonally averaged time series, and the lag-1 correlation implies a delay of 3 months. Triangles are used for monthly time series (delay 1 month), and the circles are for 2 monthly subsampled time series. In the case of EMA (Figure 3a) the open squares are for Vélez station, the filled squares are for Málaga, and the squares with crosses are for C. Pino. ( $\mathrm{f}-\mathrm{j}$ ) Relative frequencies for the standardized residuals (for all the stations and depths analyzed within each project) and the theoretical relative frequency for a normal, zero mean, unit standard deviation distribution. Residuals are grouped in bins of different size for each case. 

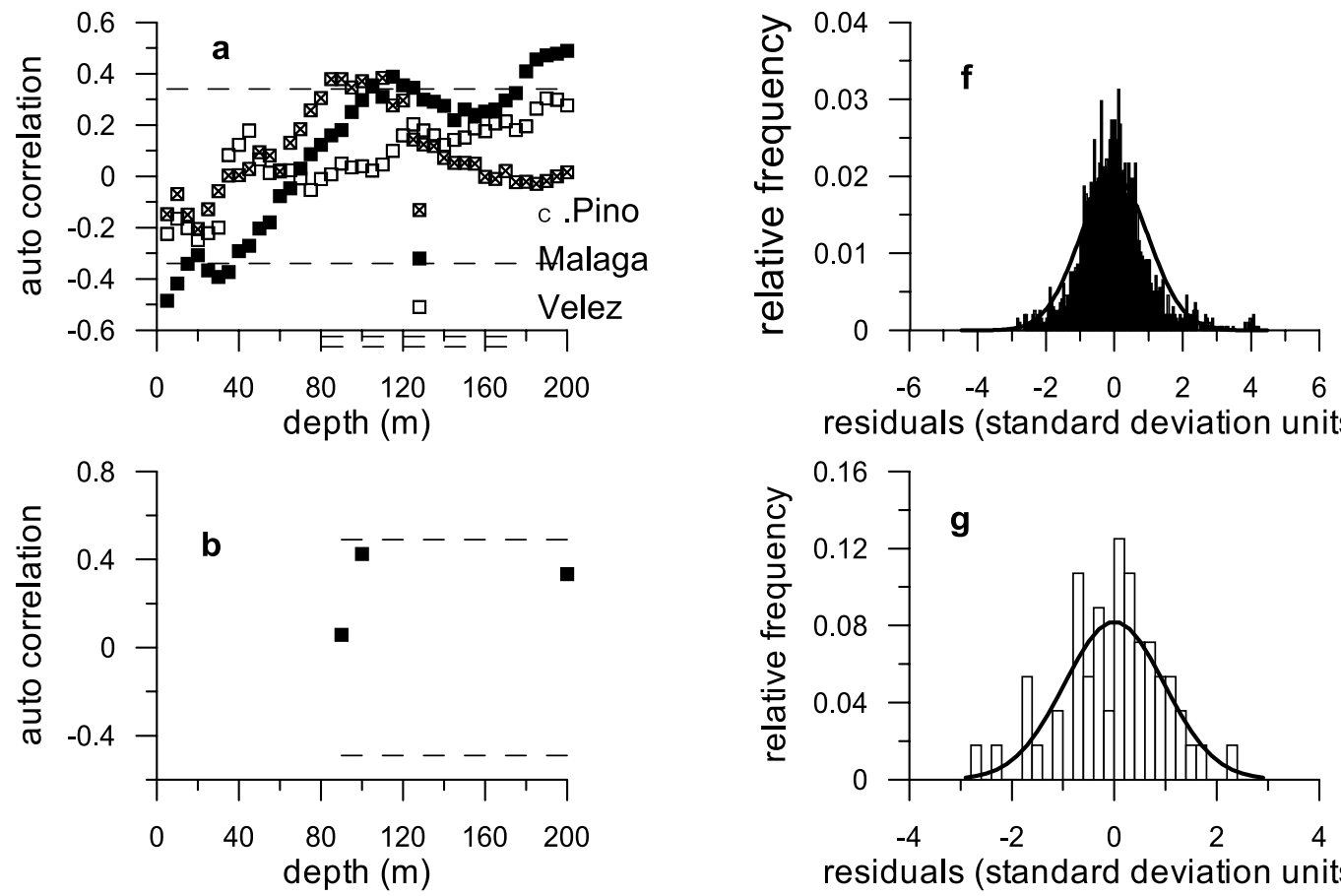

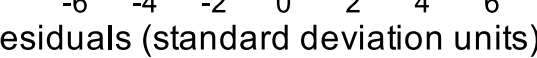
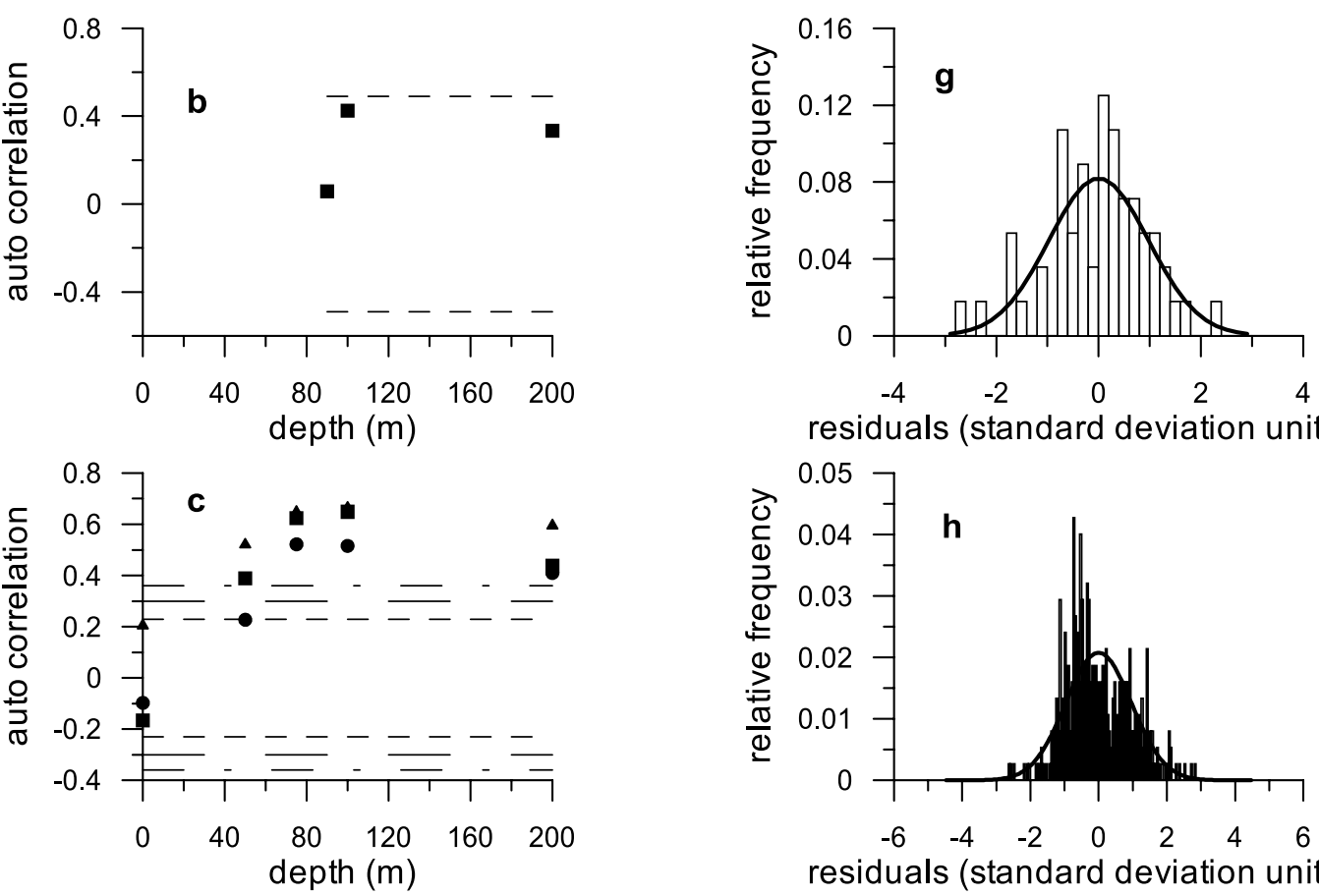

residuals (standard deviation units)

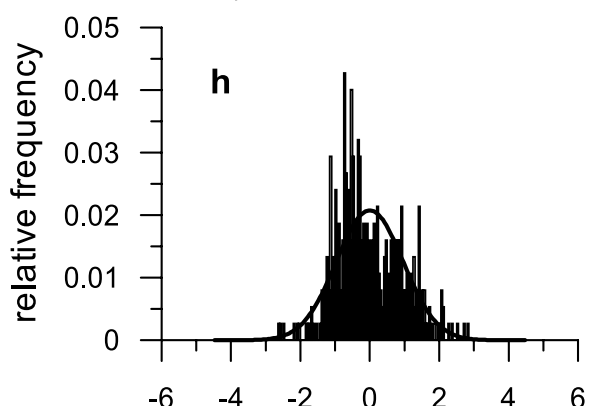

residuals (standard deviation units)
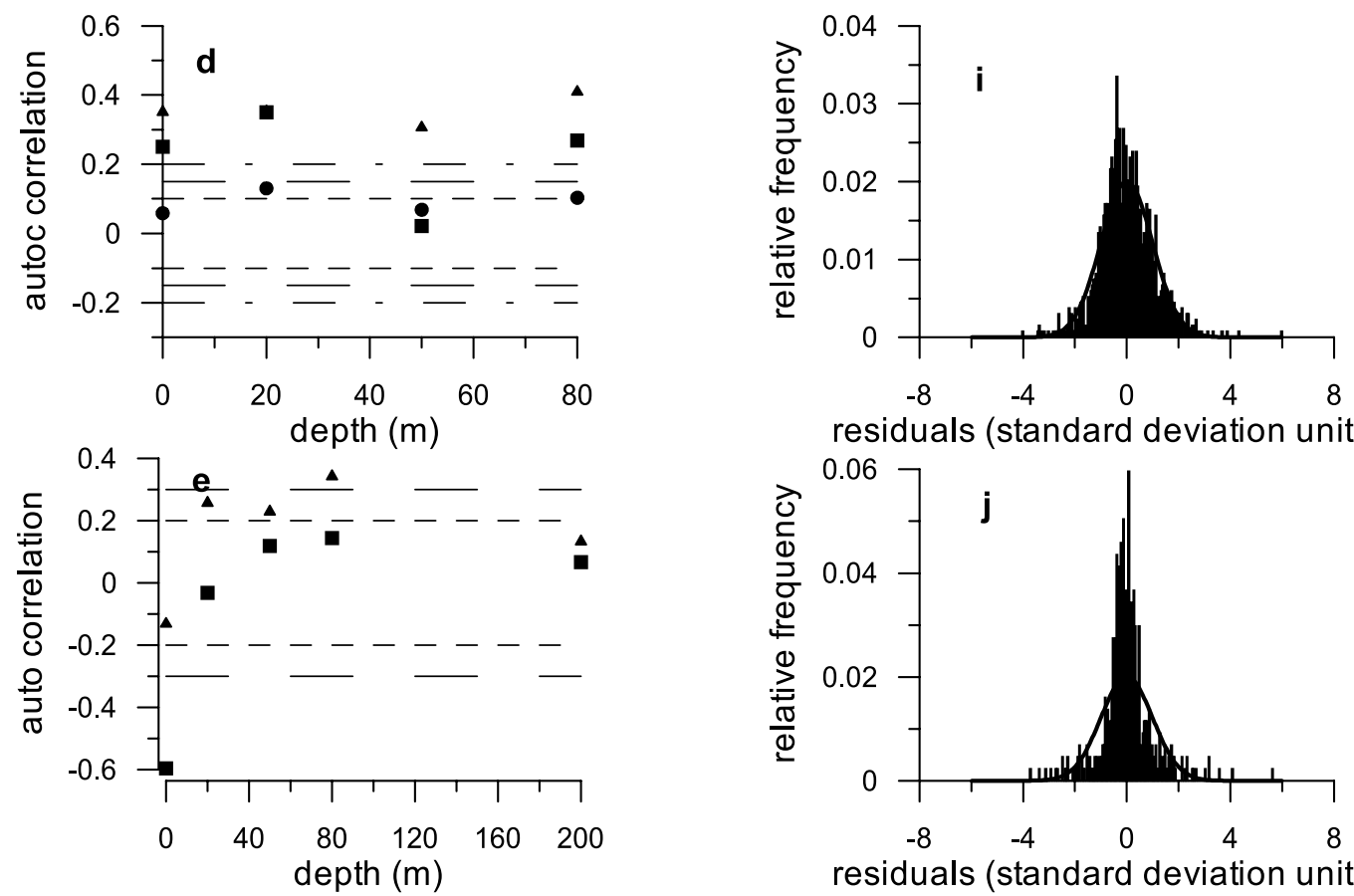

residuals (standard deviation units)

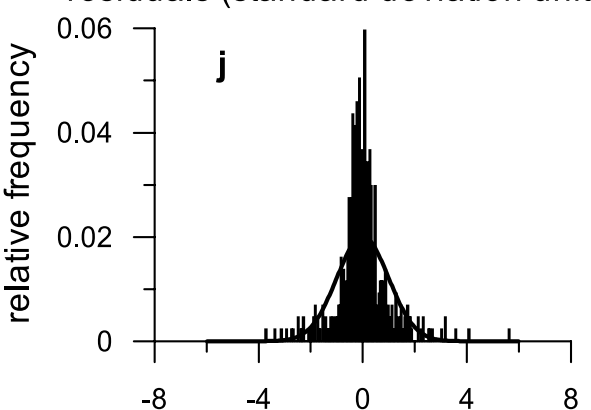

residuals (standard deviation units)

Figure 3 

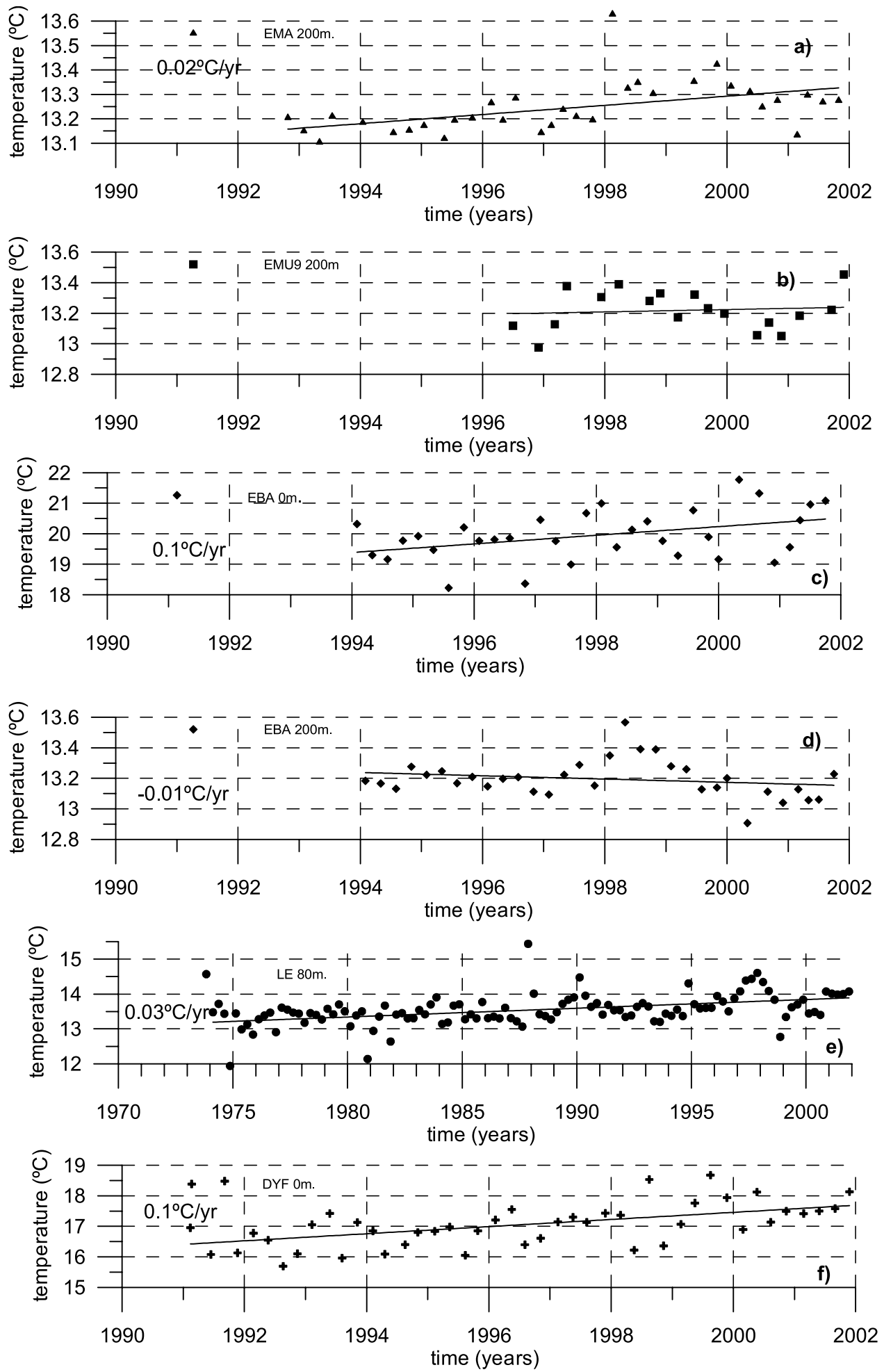

Figure 4. Time series of $(a-f)$ temperature and $(g-j)$ salinity at selected depths. In the case of monthly sampling we have used the seasonally averaged time series for the clarity of the plot.

expected value in a, let us say, warm period. Then the residuals start decreasing remaining under the fit for the 1999, 2000 and beginning of 2001 in a cool period. Figure $4 \mathrm{i}$ shows that the warm period is also a low-salinity period, while the cold period is also saltier. This indicates that these fluctuations in temperature and salinity could be linked to changes in the circulation through the Channels and shifts in the Balearic front position as suggested by Pinot et al. [2002].

[30] Figure 3d shows that LE temperature time series are significantly autocorrelated. Autocorrelation decreases for the subsampled time series, and then increases for the seasonal averages, being significant at 0,20 and $80 \mathrm{~m}$. Figure $4 \mathrm{e}$ evidences again the existence of warm and cold 

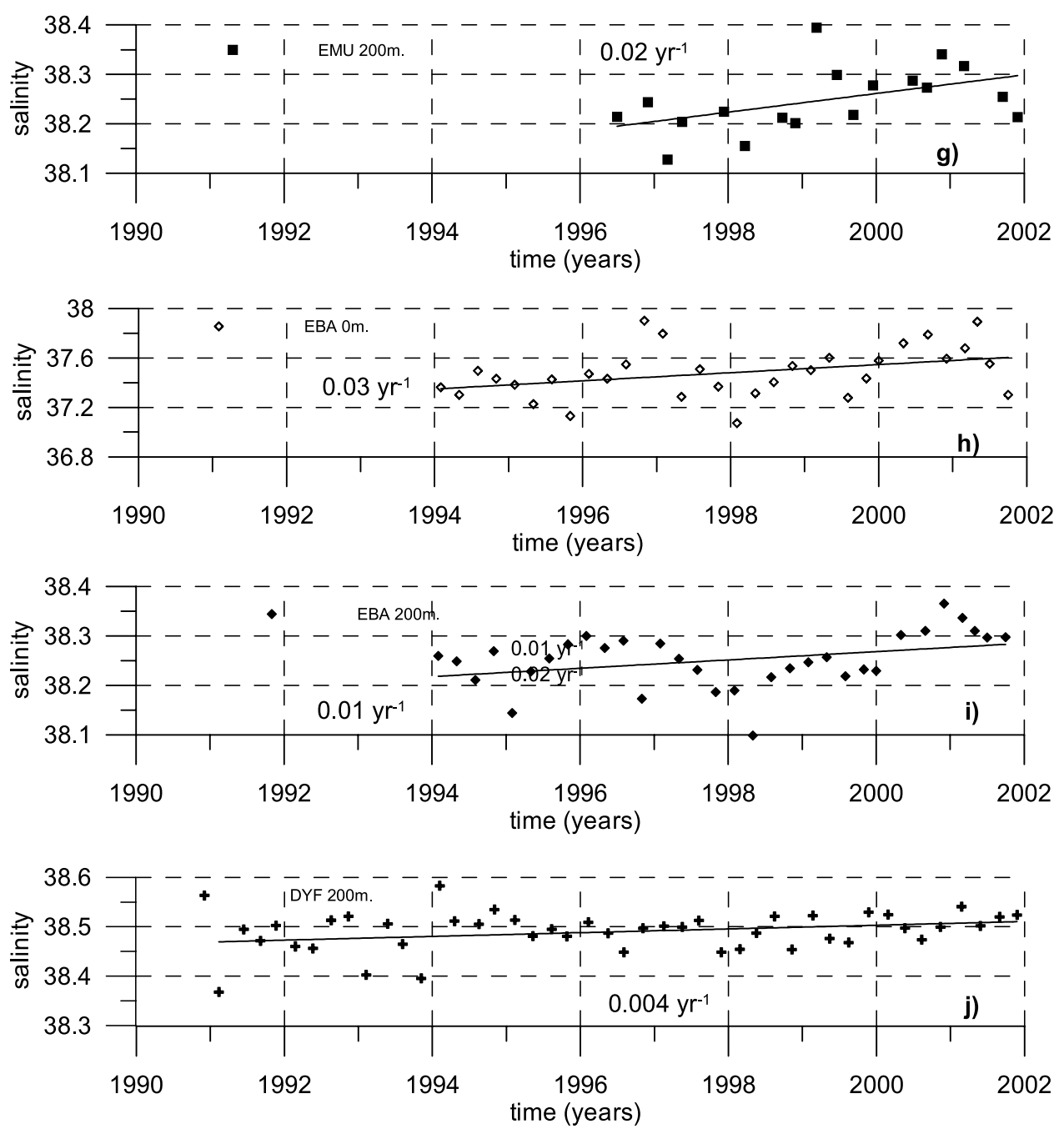

Figure 4. (continued)

alternating periods. It is specially clear the warm period initiated at the end of the 1980s and lasting until 91, then a cold period from 92 to 96 , a warm period from 97 and 98 and then cool in 99 and 2000.

[31] For the case of DYF we do not compute the correlations at 2 month delay due to the existence of some gaps. Only at $0 \mathrm{~m}$, the averaged time series is more correlated than the monthly one.

[32] The autocorrelation of the residuals evidenced in Figure 3 indicates that expression (3) is not valid and should be corrected by the effective number of degrees of freedom (NDOF) [Emery and Thomson, 1998; Chelton, 1983]. Variable $n$ in expression (3) should be substituted by $n^{*}=n / \tau, \tau$ being the integral timescale defined as $\tau=\iint_{0}^{\infty} \rho(k) d k$. This integral is usually extended to the first zero crossing of the autocorrelation function, or can be evaluated as $\tau(r)=$ $\int_{0}^{r} \rho(k) d k$ and consider the integral timescale as the first

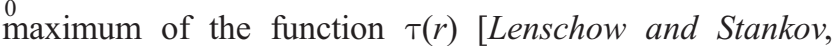
1986]. We used both procedures to get the integral timescales and no significant differences were observed. For all the seasonally averaged time series we estimated the slope of the linear trend and its confidence interval at the
0.05 level of significance considering the effective NDOF (Table 1). In Table 1 we have typed in bold those slopes which are significant at the standard significance level of 0.05 . Nevertheless, in some cases, a two-tailed $t$-test showed that the slopes estimated were different from zero at a higher confidence level. We have marked with one asterisk those slopes different from zero with $p<0.02$ (usually referred to as highly significant). We have also marked with two asterisks those slopes marginally significant $(0.05<p<0.1)$.

\section{Results}

\subsection{Ecomálaga}

[33] Table 1 shows that warming trends are significant in the deep layer of EMA continental shelf. The thickness of the layer affected by these trends increases from C. Pino to Vélez, being the shallowest trend detected in C. Pino at $175 \mathrm{~m}$ and at 150 and $75 \mathrm{~m}$ in Málaga and Vélez respectively. This could indicate that the observed warming is related to the Mediterranean waters rather than to the AW. To check this hypothesis we analyzed the time series of sea surface temperature in the Fuengirola beach (which is the best sampled time series in EMA area). The slope of 
Table 1. Slope Estimation and 95\% Confidence Intervals for the Different Time Series Analyzed ${ }^{\mathrm{a}}$

\begin{tabular}{|c|c|c|c|c|c|c|c|c|}
\hline Depth & C. Pino & Málaga & Vélez & EMU6 & EMU9 & EBA & LE & DYF \\
\hline \multicolumn{9}{|c|}{ Temperature } \\
\hline Surface & $0.167 \pm 0.130^{b}$ & $0.078 \pm 0.186$ & $0.106 \pm 0.185$ & $-0.169 \pm 0.378$ & $-0.178 \pm 0.449$ & $0.136 \pm 0.128$ & $0.039 \pm 0.017^{b}$ & $0.106 \pm 0.085^{b}$ \\
\hline 10 & $0.135 \pm 0.145^{\mathrm{c}}$ & $0.092 \pm 0.172$ & $0.119 \pm 0.171$ & & & & & \\
\hline 15 & $0.123 \pm 0.142^{\mathrm{c}}$ & $0.064 \pm 0.168$ & $0.110 \pm 0.139$ & & & & & \\
\hline 20 & $0.085 \pm 0.134$ & $0.041 \pm 0.172$ & $0.025 \pm 0.153$ & & & & $0.044 \pm \mathbf{0 . 0 1 4}^{\mathrm{b}}$ & $0.115 \pm 0.08^{b}$ \\
\hline 25 & $0.048 \pm 0.125$ & $0.038 \pm 0.166$ & $-0.002 \pm 0.151$ & & & & & \\
\hline 30 & $0.028 \pm 0.127$ & $0.032 \pm 0.160$ & $0.035 \pm 0.130$ & & & & & \\
\hline 35 & $0.024 \pm 0.110$ & $0.054 \pm 0.140$ & $0.076 \pm 0.165$ & & & & & \\
\hline 40 & $0.016 \pm 0.108$ & $0.067 \pm 0.115$ & $0.085 \pm 0.146$ & & & & & \\
\hline 45 & $0.006 \pm 0.091$ & $0.079 \pm 0.103$ & $0.075 \pm 0.131$ & & & & & \\
\hline 50 & $-0.004 \pm 0.085$ & $0.068 \pm 0.095$ & $0.068 \pm 0.111$ & & & $-0.059 \pm 0.175$ & $0.038 \pm 0.015^{\mathrm{b}}$ & $0.035 \pm 0.033$ \\
\hline 55 & $-0.023 \pm 0.080$ & $0.078 \pm 0.086^{\mathrm{c}}$ & $0.063 \pm 0.085$ & & & & & \\
\hline 60 & $-0.029 \pm 0.070$ & $0.066 \pm 0.077^{\mathrm{c}}$ & $0.072 \pm 0.092$ & & & & & \\
\hline 65 & $-0.016 \pm 0.061$ & $0.068 \pm 0.070^{\mathrm{c}}$ & $0.071 \pm 0.086$ & & & & & \\
\hline 70 & $-0.009 \pm 0.063$ & $0.053 \pm 0.084$ & $0.070 \pm 0.071^{\mathrm{c}}$ & & & & & \\
\hline 75 & $-0.004 \pm 0.055$ & $0.048 \pm 0.080$ & $0.072 \pm 0.061^{b}$ & & & $-0.052 \pm 0.168$ & & \\
\hline 80 & $0.015 \pm 0.056$ & $0.047 \pm 0.068$ & $0.067 \pm \mathbf{0 . 0 5 8}^{\mathrm{b}}$ & & & & $0.026 \pm 0.012^{b}$ & $0.011 \pm 0.016$ \\
\hline 85 & $0.020 \pm 0.056$ & $0.043 \pm 0.065$ & $0.062 \pm 0.051^{\mathrm{b}}$ & & & & & \\
\hline 90 & $0.022 \pm 0.055$ & $0.038 \pm 0.059$ & $0.058 \pm 0.048^{b}$ & $-0.021 \pm 0.14$ & & & & \\
\hline 95 & $0.024 \pm 0.051$ & $0.034 \pm 0.057$ & $0.054 \pm 0.045^{\mathrm{b}}$ & & & & & \\
\hline 100 & $0.025 \pm 0.049$ & $0.037 \pm 0.059$ & $0.055 \pm 0.044^{b}$ & & $0.007 \pm 0.190$ & $-0.004 \pm 0.146$ & & \\
\hline 105 & $0.025 \pm 0.049$ & $0.032 \pm 0.045$ & $0.053 \pm 0.039^{\mathrm{b}}$ & & & & & \\
\hline 110 & $0.025 \pm 0.051$ & $0.034 \pm 0.041^{\mathrm{c}}$ & $0.053 \pm 0.039^{b}$ & & & & & \\
\hline 115 & $0.012 \pm 0.035$ & $0.034 \pm 0.037^{\mathrm{c}}$ & $0.048 \pm 0.030^{b}$ & & & & & \\
\hline 120 & $0.012 \pm 0.032$ & $0.036 \pm 0.038^{\mathrm{c}}$ & $0.042 \pm 0.027^{\mathrm{b}}$ & & & & & \\
\hline 125 & $0.012 \pm 0.042$ & $0.034 \pm 0.036^{\mathrm{c}}$ & $0.036 \pm 0.026^{b}$ & & & & & \\
\hline 130 & $0.014 \pm 0.037$ & $0.032 \pm 0.036^{\mathrm{c}}$ & $0.036 \pm 0.023^{b}$ & & & & & \\
\hline 135 & $0.014 \pm 0.034$ & $0.029 \pm 0.034^{\mathrm{c}}$ & $0.035 \pm 0.022^{\mathrm{b}}$ & & & & & \\
\hline 140 & $0.015 \pm 0.023$ & $0.026 \pm 0.032$ & $0.034 \pm 0.021^{b}$ & & & & & \\
\hline 145 & $0.015 \pm 0.022$ & $0.025 \pm 0.027^{\mathrm{c}}$ & $0.032 \pm 0.019^{\mathrm{b}}$ & & & & & \\
\hline 150 & $0.016 \pm 0.021$ & $0.026 \pm 0.024$ & $0.032 \pm 0.019^{b}$ & & & & & \\
\hline 155 & $0.016 \pm 0.020$ & $0.027 \pm 0.021^{b}$ & $0.029 \pm 0.018^{b}$ & & & & & \\
\hline 160 & $0.015 \pm 0.018$ & $0.025 \pm 0.018^{b}$ & $0.028 \pm 0.017^{\mathrm{b}}$ & & & & & \\
\hline 165 & $0.014 \pm 0.017^{\mathrm{c}}$ & $0.025 \pm 0.015^{\mathrm{b}}$ & $0.026 \pm 0.016^{b}$ & & & & & \\
\hline 170 & $0.014 \pm 0.016^{\mathrm{c}}$ & $0.026 \pm 0.014^{b}$ & $0.024 \pm 0.015^{b}$ & & & & & \\
\hline 175 & $0.013 \pm \mathbf{0 . 0 1 3}$ & $0.026 \pm 0.013^{b}$ & $0.023 \pm 0.015^{b}$ & & & & & \\
\hline 180 & $0.012 \pm 0.012$ & $0.024 \pm \mathbf{0 . 0 1 3}^{\mathrm{b}}$ & $0.021 \pm 0.014^{b}$ & & & & & \\
\hline 185 & $0.012 \pm \mathbf{0 . 0 1 1}^{\mathrm{b}}$ & $0.024 \pm \mathbf{0 . 0 1 3}^{\mathrm{b}}$ & $0.019 \pm 0.014^{b}$ & & & & & \\
\hline 190 & $0.013 \pm \mathbf{0 . 0 0 9}^{\mathrm{b}}$ & $0.024 \pm \mathbf{0 . 0 1 3}^{\mathrm{b}}$ & $0.019 \pm 0.014^{b}$ & & & & & \\
\hline 195 & $0.013 \pm 0.008^{b}$ & $0.023 \pm 0.012^{b}$ & $0.019 \pm 0.013^{b}$ & & & & & \\
\hline \multirow[t]{2}{*}{200} & $0.013 \pm \mathbf{0 . 0 0 8}^{\mathrm{b}}$ & $0.022 \pm \mathbf{0 . 0 1 2}^{\mathrm{b}}$ & $0.018 \pm 0.012^{b}$ & & $0.02 \pm 0.072$ & $-0.012 \pm 0.028$ & & $0.002 \pm 0.011$ \\
\hline & & & & Salini & & & & \\
\hline Surface & & & & $0.01 \pm 0.16$ & $-0.02 \pm 0.1$ & $0.034 \pm 0.037^{\mathrm{c}}$ & & $-0.004 \pm 0.022$ \\
\hline 20 & & & & & & & & $-0.001 \pm 0.016$ \\
\hline 50 & & & & & & $0.032 \pm 0.058$ & & $0.003 \pm 0.010$ \\
\hline 75 & & & & & & $0.027 \pm 0.048$ & & \\
\hline 80 & & & & & & & & $-0.001 \pm 0.010$ \\
\hline 90 & & & & $0.039 \pm 0.038$ & & & & \\
\hline 100 & & & & & $0.038 \pm 0.048$ & $0.020 \pm 0.037$ & & \\
\hline 200 & & & & & $0.024 \pm \mathbf{0 . 0 2}^{\mathrm{b}}$ & $0.009 \pm 0.013$ & & $0.004 \pm 0.004$ \\
\hline
\end{tabular}

${ }^{a}$ Expressions (2) and (3) are used using the effective number of degrees of freedom, defined as the length of the time series divided by the integral timescale of the series (see text). Significant values at the 0.05 significance level are in bold.

${ }^{\mathrm{b}}$ Highly significant values $(p<0.02)$.

${ }^{\mathrm{c}}$ Marginally significant values $(0.05<p<0.1)$.

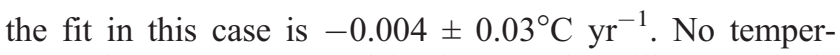
ature changes were found in the AW that fills Fuengirola beach.

[34] Salinity remained stationary for the period analyzed, no trends were detected in none of the time series and they have not been included in Table 1 to avoid an excessive length. As commented in section 2.1 (Figure 2a) the LIW influence is not detected in the EMA continental shelf. These results could indicate that the warming of the Mediterranean waters observed in EMA area during the 1990s cannot only be the consequence of changes imported from the eastern basin. Figure $4 \mathrm{a}$ shows the temperature time series in EMA at $200 \mathrm{~m}$ (the mean value of C. Pino,
Málaga and Vélez). The temperature increase is evident as well as some interesting phenomena such as the exceptionally warm 1997-1998 winter [García-Górriz and Carr, 2001]. In autumn 92, in situ temperature in EMA (200m) was around $13.18^{\circ} \mathrm{C}$. In the same survey, in Málaga station, temperature was $12.97^{\circ} \mathrm{C}$ and salinity 38.26 . These values could indicate the presence of WIW in the area of Málaga Bay during this autumn. WIW has not been found again in any of the EMA surveys.

\subsection{Ecomurcia}

[35] EMU stations show no significant temperature trends, nor does salinity in the surface layer. Salinity at 
$90 \mathrm{~m}$ (EMU6), and $200 \mathrm{~m}$ (EMU9) has increased during the period 1996-2001 (Table 1). Figure 4b shows clearly a low-frequency oscillatory behavior of temperature at $200 \mathrm{~m}$, with a cold period during the beginning of the series, then a warm period from 1997 to 1998, then a temperature decrease until the end of 2000, and again an increasing period during 2001. Temperature values in 1996 are one of the lowest of this series. In situ temperature is lower than $13^{\circ} \mathrm{C}$ in November 1996. It was also lower $\left(12.975^{\circ} \mathrm{C}\right)$ in June 1996 , though the seasonal cycle subtraction does not allow to appreciate it in Figure 4b. In July 2000, temperature at $200 \mathrm{~m}$ was 12.913. The salinity corresponding to these cold temperatures were $38.19,38.26$ and 38.26 respectively. These results indicate that WIW can reach the Murcia region in cold years.

\subsection{Ecobaleares}

[36] Figure 3c shows that EBA time series are one of the most strongly autocorrelated. As pointed out by Pinot et al. [2002], warm years could be associated to the absence of WIW what could favor the intrusion of fresh Atlantic water to the north of the Islands. Pinot et al. [2002] suggested that the low-salinity and warm AW could even prevent the WIW formation producing several years lasting warm and fresh periods. On the other hand, cold winters associated to large amounts of WIW production can block the AW progression to the north. Even in the case that this hypothesis was not true, it still holds that winter conditions would have some influence on the following spring water masses, and temperature and salinity anomalies corresponding to consecutive seasons would be strongly correlated. The integral timescale for the 0,50 , 75,100 and $200 \mathrm{~m}$ temperature time series are 3, 6.5, 7.4, 4 and 7.2 months. On the average the integral timescale is 5.6 months indicating that consecutive seasonal anomalies are correlated. None of the temperature trends detected for the EBA temperature time series are statistically significant except that corresponding to the surface (Table 1, Figure $4 \mathrm{c}$ ). For the salinity time series the integral timescales are 3.9, 4.4, 6.6, 7.7 and 5.6. None of the trends detected (Table 1) are significant.

[37] Figure 4d shows quite clearly this kind of lowfrequency fluctuations. Temperature anomalies show the existence of a cold period during 1996 and the beginning of 1997. Though they still remained negative, during the beginning of 1997 anomalies started increasing reaching maximum values in spring 1998 and remaining positive until the beginning of 1999. Years 2000 and 2001 seem to correspond to a cold period although the anomalies tend to increase to the end of 2001.The situation is even clearer for the $200 \mathrm{~m}$ salinity time series (Figure 4i). From mid 1995 to mid 1997 the salinity is higher than the expected value coinciding with the first cold period, then there is a period of low salinity values from mid 1997 to the end of 1999 corresponding to the warm period, and a final increase of salinity for the final cold period of our time series. The consistency between temperature and salinity time series and the high autocorrelation of the residuals support the hypothesis that the trends (if existing) in the Balearic Channels are superimposed on low-frequency oscillations probably linked to the shift of the Balearic front and the latitude reached by the AW.

\subsection{L'Estartit}

[38] All depths exhibited intense trends ranging from 0.03 to $0.04^{\circ} \mathrm{C} \mathrm{yr}^{-1}$ (Table 1), which is an order of magnitude higher than previously reported trends in the western Mediterranean for the LIW and WMDW.

[39] Figure 3d shows that the lag-1 autocorrelation function is statistically significant for the monthly time series at the four depths, while consecutive measurements seem to be uncorrelated for the subsampled time series at a 2 month time step. The seasonally averaged time series are again autocorrelated at 0,20 and $80 \mathrm{~m}$. As mentioned in section 3, our hypothesis is that the time series are affected by some sort of noise or high-frequency variability that reduces or obscures the low-frequency oscillations present in our time series and likely linked to large-scale spatial patterns. This noise would be correlated over a 1 month period. For the bimonthly time series it is still present in the time series, but could be uncorrelated as it probably has timescales shorter than 2 months. It still has the capability of masking the lowfrequency behavior, but its serial correlation is diminished by the subsampling. When we average over each season of the year this noise is filtered out and large timescales arise more clearly. Concerning the 1990s decade, there is a warm period during 1989 and 1990 and then a cold period from 1992 to mid 1996, partially overlapping with the cold period reported in the other areas. Then the warm period for 1997 and half 1998, finalizing with a temperature decrease during the end of the series (Figure 4e). Nevertheless the timescales in LE do not seem to be as long as in EBA and the integral timescales for the monthly time series are $1.5,1.6,1.3$ and 1.9 months, for the 2 monthly time series $2.2,2.3,2.1$ and 2.4 months, and 3.8, 4.1, 3.1 and 3.7 months for the seasonally averaged time series.

\subsection{Dyfamed}

[40] Temperature time series in DYF station only exhibited positive trends in the very upper layer $(0,20$, $50 \mathrm{~m}$ ), not being detected in the 80 and $200 \mathrm{~m}$ time series (Table 1). Although these trends could be considered unrealistically high at 0 and $20 \mathrm{~m}$, we have to remark that they are not different from the EMA or LE trends within the $95 \%$ confidence interval. An important difference respect to the other areas analyzed is that the salinity increased at $200 \mathrm{~m}$ while the temperature remained stationary at the same depth. We have to point out that there is a strong influence of the LIW in the upper layer at this site. This influence is observed from the $90 \mathrm{~m}$ depth. The LIW core is located on the average at $275 \mathrm{~m}$ (section 2.1, Figure 2d). Another difference is that the low-frequency variability observed is different to the one already described. For instance, the very clear warm period centered in the 1997-1998 winter is not observed in DYF station. At $0 \mathrm{~m}$, fall 1997 and winter and spring 1998 are not abnormally high (Figure 4f), neither they are at $200 \mathrm{~m}$ (not shown). The warmest temperature in 1998 (both at 0 and $200 \mathrm{~m}$ ) is in summer and salinity shows a relative maximum (though not very pronounced) contrary to the salinity decrease in EBA. In conclusion, DYF station has a different behavior to the nearby LE and EBA stations, 
Ibiza Channel Mallorca Channel

a) $05 / 96$
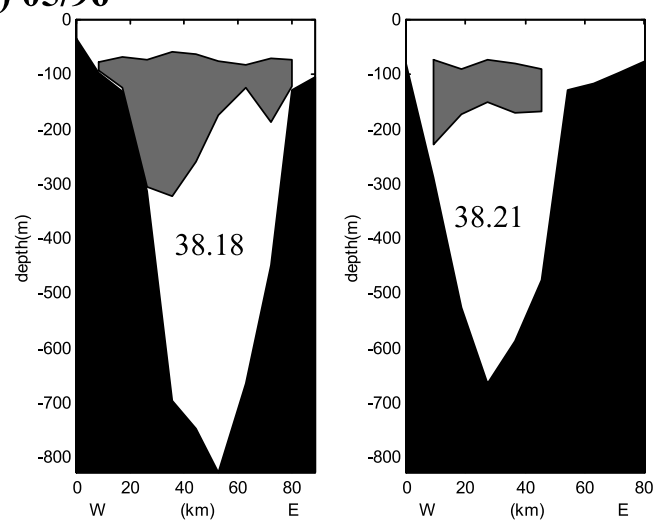

c) $06 / 098$

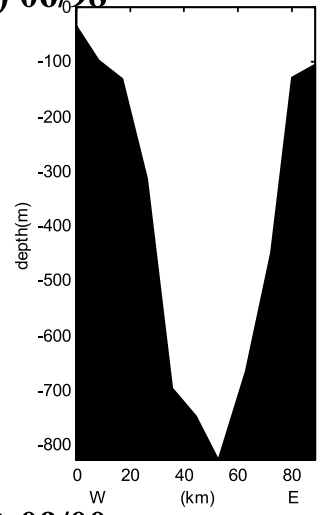

e) $09 / 00$

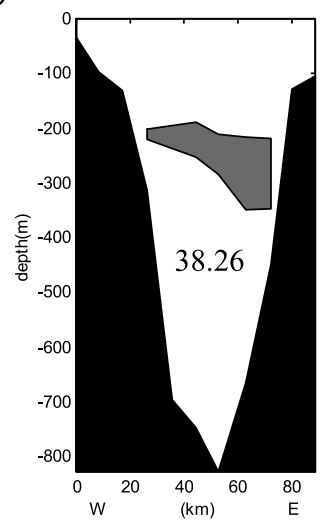

g) $03 / 01$
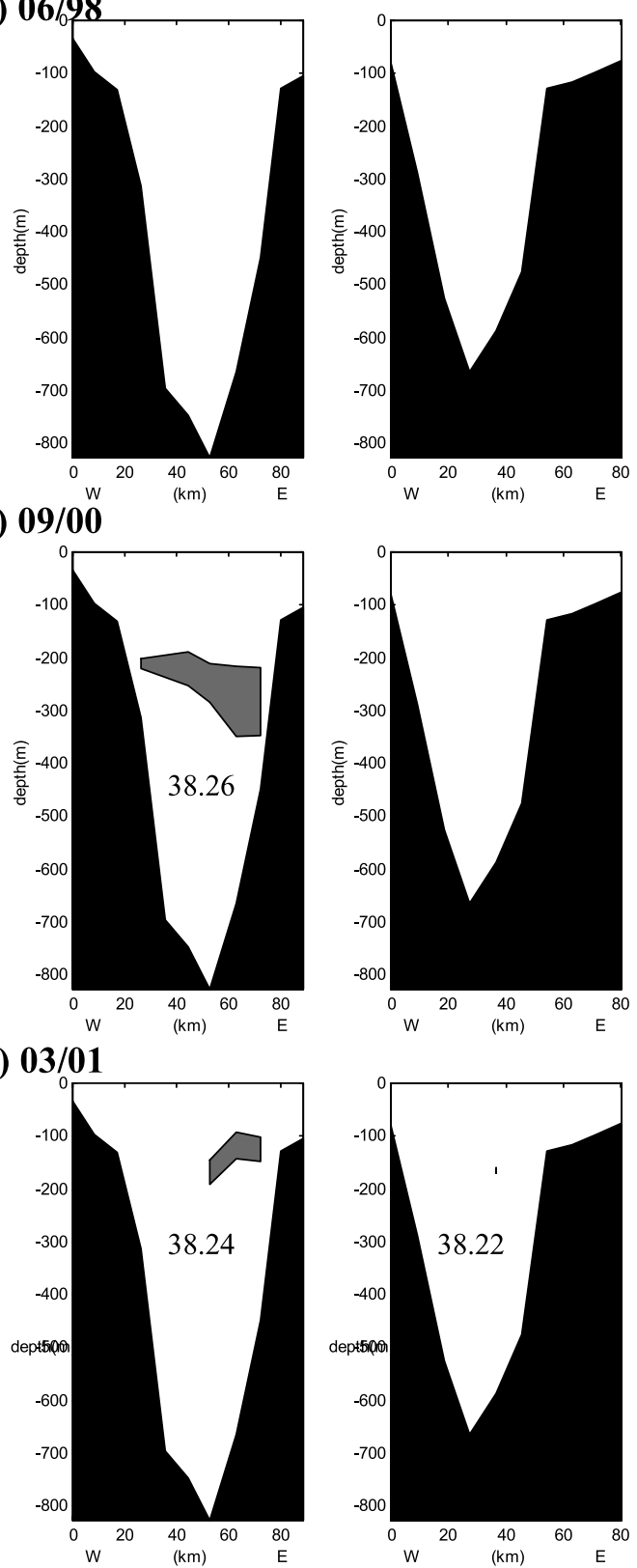

Ibiza Channel Mallorca Channel

b) $05 / 97$
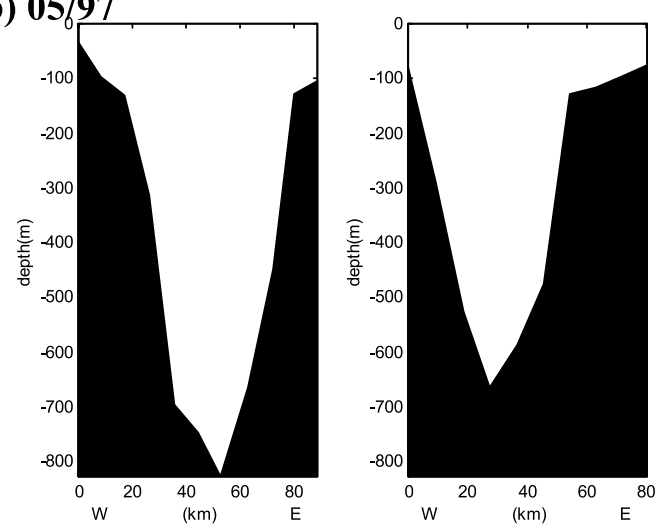

d) $05 / 99$
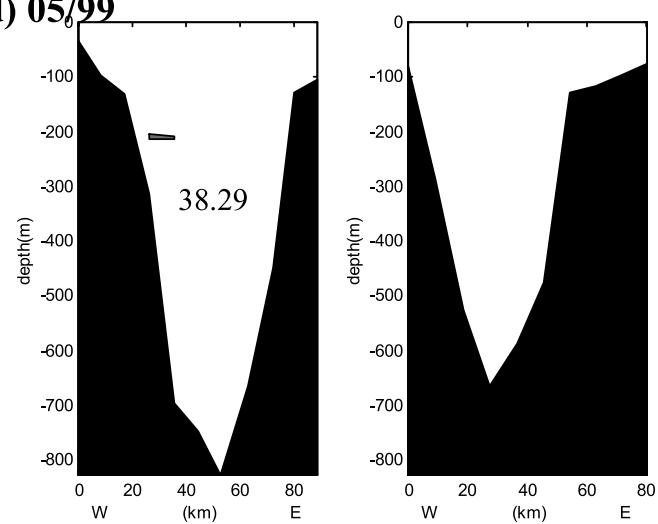

f) $11 / 00$
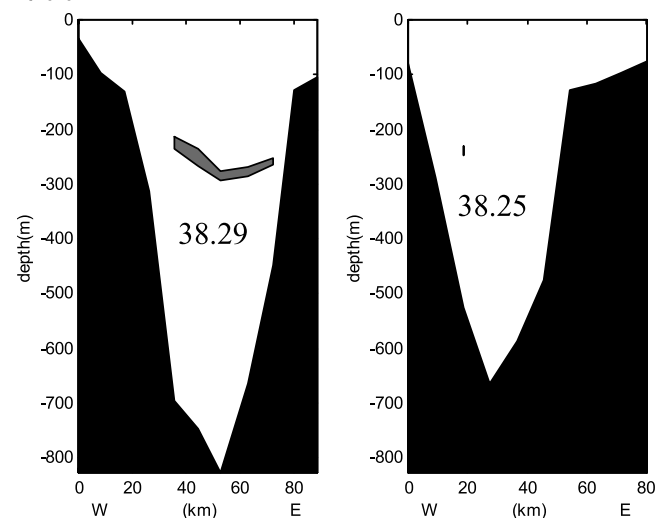

h) $11 / 01$
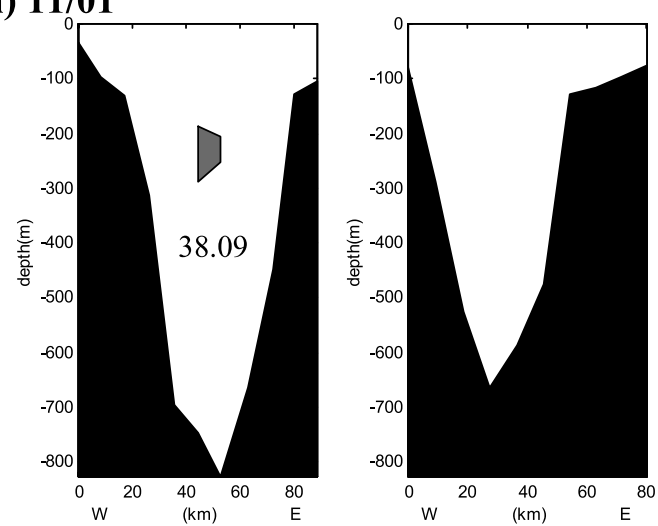

Figure 5. WIW layer thickness and its mean salinity for the CIRBAL cruises. 


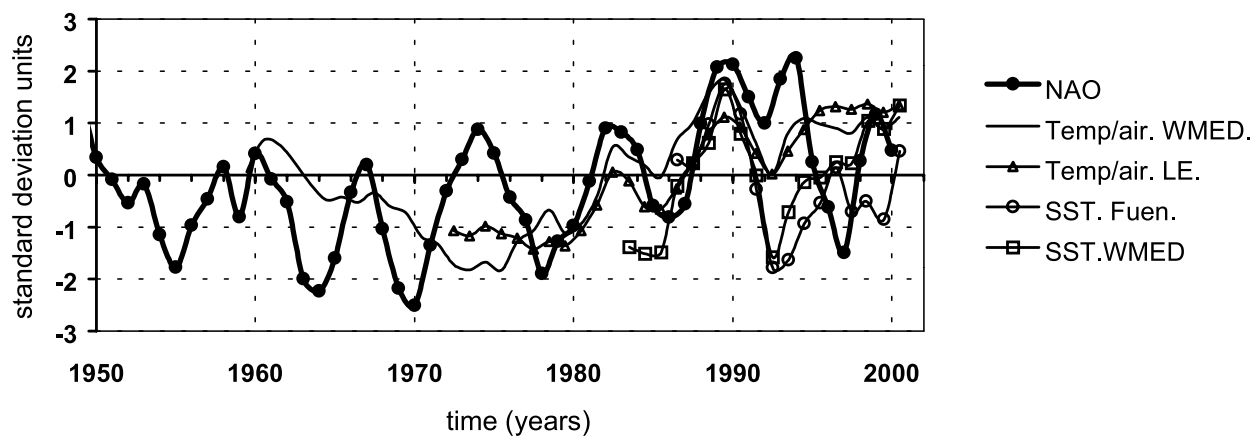

Figure 6. Winter NAO index and air temperature in the western Mediterranean (WMED) and in LE station. Sea surface temperature in the Fuengirola Beach and sea surface temperature in the WMED. The western Mediterranean is represented by the rectangle $2^{\circ} \mathrm{W}-10^{\circ} \mathrm{E}$ and $35^{\circ}-44^{\circ} \mathrm{N}$. All time series are made of annual standardized residuals and have been smoothed by a 3 year moving average.

probably due to its open sea location and the influence of the LIW.

\subsection{Balearic Channels}

[41] Figures $5 \mathrm{a}-5 \mathrm{~h}$ show the thickness of the WIW within the Balearic channels for each CIRBAL project survey (Figure 1d). The shaded area is that occupied by waters with potential temperature lower than $13^{\circ} \mathrm{C}$. We have also included the mean salinity value corresponding to the WIW layer defined above. When WIW is present in the channels, the layer thickness is always larger in the Ibiza than in the Mallorca channel, reflecting that this is the main path of this water mass toward the south. The largest amount of WIW was found in spring 1996 coinciding with the cold period evidenced in EMU, EBA and LE stations. Previous sections also showed the temperature increase from mid 1997 to 1998, when maximum values were found. This is coincident with the absence of WIW in May 1997 and June 1998 (Figures 5b and 5c). In the years 2000 and 2001, WIW was found again coinciding with the temperature decrease along the Spanish continental shelf. The largest volumes of WIW are expected to be found after the winter formation of this water mass. Although there are not spring cruises available in 2000 , we have to remark that the existence of WIW in summer can be considered as an indication of larger amounts of WIW in the previous spring. The persistence of WIW in autumn 2000 in both channels could indicate the formation of large amounts of this water mass during the previous winter or an early formation of it in winter 2000-2001. In spring 2001, WIW was detected in both channels, although the layer thickness in the Mallorca channel was very small. This water mass could still be identified in autumn 2001. Taking into account the irregularity of these surveys, we can confirm that the appearance/ disappearance of WIW coincides, in a rough way, with the cold/warm periods identified in the other time series and therefore it can be considered as an indicator of the climatic variability in the western Mediterranean continental shelf.

\subsection{Meteorological Conditions and Teleconnections}

[42] Monthly time series of air temperature in LE (19712001, Figure 6) and Fuengirola beach (1992-2001, not shown) show warming trends around $0.11^{\circ} \mathrm{C} \mathrm{yr}^{-1}$. Both time series are poorly correlated, but this correlation increases to 0.76 if annually averaged time series are used. This indicates that monthly values are affected by local processes, while interannual variability is driven by more global processes affecting to both locations. This is also evidenced by the good correlation between annual air temperature values in LE and in the western Mediterranean (WMED) (Figure 6). Time series in Figure 6 have been smoothed with a 3 year moving average confirming our hypothesis that lower-frequency oscillations are associated to larger spatial scales increasing the correlation between distant points and filtering out local factors. The warming trend for the WMED air temperature is $0.05^{\circ} \mathrm{C} \mathrm{yr}^{-1}$. This value is lower than that for LE air temperature because WMED time series extends to 1960, with a cold period from the early 1960 s to mid-1970s. From the mid-1970s to 2001 there is a clear warming trend in the air temperature that is coincident with increasing values of the NAO index. It is also important to remark the good agreement between the low-frequency oscillations of the NAO index and those of air temperature in LE and WMED (Figure 6) indicating that the shift from low and even negative values of the NAO index to a positive phase during this period, could be the reason for increasing air temperatures in the western Mediterranean [Xoplaki et al., 2003]. Nevertheless we have to point out that the NAO index shows a good correlation with air and sea surface temperatures from mid seventies to 1992 , but after this year this in phase relation is broken. While temperatures have continued increasing, the NAO index has shifted to less positive values and even negative ones in 1996 and 2001.

[43] There is also a good agreement between air and sea surface temperature anomaly time series (original time series minus linear trends and seasonal cycles). This correlation is 0.7 and 0.6 for the annual time series of air and SST in LE and Fuengirola respectively. If we use the air and SST in WMED, this value increases to 0.87 .

\section{Summary and Conclusions}

[44] We have analyzed temperature and salinity time series in coastal areas of the western Mediterranean during the 1990s and from mid-1970s in some cases. Most of the stations considered were located over the continental shelf. The only exception was DYF station, located in an open sea area in the Ligurian Sea. 
[45] Positive temperature trends have been observed in the uppermost part of the water column in DYF station $(0$, 20 and $50 \mathrm{~m})$. At these depths the salinity remained stationary. At $200 \mathrm{~m}$ the salinity time series showed a positive and significant trend while no trends were detected for temperature. LE station is in the inner part of the continental shelf of the Catalan Sea. Significant and intense warming trends $\left(0.03^{\circ}-0.04^{\circ} \mathrm{C} \mathrm{yr}^{-1}\right)$ were detected along the water column $(0,20,50$ and $80 \mathrm{~m})$. The heat content of the water column increased by $3.4 \times 10^{8} \mathrm{~J} \mathrm{~m}^{-2}$, or equivalently at a rate of $0.4 \mathrm{~W} \mathrm{~m}^{-2}$ over the 1974-2001 period. The only significant trend in EBA station was found in the sea surface temperature time series. Salinity increased during the $1990 \mathrm{~s}$ at the five depths sampled $(0,50,75,100$ and $200 \mathrm{~m}$ ), but none of these salinity trends were statistically significant. Time series of anomalies in EBA station showed a high autocorrelation. This seems to indicate that the processes that drive the oscillations in temperature and salinity around the Balearic Islands and channels are not local ones. These fluctuations could be the result of largespatial-scale processes affecting to larger areas of the northwestern Mediterranean, as the production of WIW, the north-south displacements of the Balearic front and the AW circulation through the Balearic channels [Pinot et al., 2002]. We have also evidenced an interannual variability in the presence/absence of WIW in the Balearic channels. Our data set indicates, as previously suggested [Pinot et al., 2002; Vargas-Yáñez et al., 2002], that this water mass, formed during severe winters in the continental shelf areas of the northwestern Mediterranean, could be a good climatic indicator. Cold winters are followed by large volumes of WIW during spring in the Balearic channels, while mild winters would be followed by the absence of this water mass. The northern current flowing along the Spanish continental slope would be the oceanographic feature connecting the northern regions where WIW is formed with the Balearic channels (mainly the Ibiza one) and areas to the south. Cold winters such as those of 1995-1996 and 19992000 are followed by large volumes of WIW in the channels and WIW was also detected to the south in EMU9 station. No temperature trends were observed in EMU stations during the period analyzed. Salinity increased at $90 \mathrm{~m}$ in EMU6 and at $200 \mathrm{~m}$ in EMU9, being both trends statistically significant. EMU9 Salinity at $100 \mathrm{~m}$ had also a positive trend, but not significant.

[46] Positive and intense trends have been detected during the $1990 \mathrm{~s}$ in the EMA region $\left(\sim 0.02{ }^{\circ} \mathrm{C} \mathrm{yr}^{-1}\right)$. No significant changes were found in the salinity time series. The extension of the water column affected by these warming trends decreased from the easternmost station (Vélez) to the westernmost one (Cape Pino), located under a more direct influence of the Atlantic current flowing into the Alboran Sea. Temperature trends were statistically significant in Vélez from 75 to $200 \mathrm{~m}$, from 150 to $200 \mathrm{~m}$ in Málaga, and from 175 to $200 \mathrm{~m}$ in Cape Pino. The heat content of the water column increased at a rate of $1.3,1.2$ and $0.7 \mathrm{~W}$ $\mathrm{m}^{-2}$ in Vélez, Málaga and C. Pino respectively. Only the heat content increase in Vélez was statistically significant.

[47] Air temperature in Fuengirola (1992-2001) and in LE (1971-2001) increased at a rate of $0.1^{\circ} \mathrm{C} \mathrm{yr}^{-1}$. This air temperature increase does not seem to be a local phenomenon. Anomaly time series (after subtracting the linear trend and the seasonal cycle) show a good correlation between Fuengirola and LE $(r=0.76)$. Another fact indicating the large-scale (basin-wide) character of the air warming is that the air temperature time series from 1960 to 2001 in a larger area of the western Mediterranean $\left(2^{\circ} \mathrm{W}-10^{\circ} \mathrm{E}, 35^{\circ}-44^{\circ} \mathrm{N}\right)$ showed a positive trend of $0.05^{\circ} \mathrm{C} \mathrm{yr}^{-1}$. The discrepancy with the trend observed for LE and Fuengirola was caused by the cold period from the beginning of the 1960s to mid1970s. Previous works [Xoplaki et al., 2003] have also reported a warming of the air temperature during the second half of the 20th century. As pointed out by Xoplaki et al. [2003], Rixen et al. [2005], and our own analysis (Figure 6 and section 4.7), the air temperature increase from mid1970 s is coincident with a shift in the NAO index from a negative to a positive phase.

[48] As already commented, air temperature has increased both in LE and Fuengirola. SST has increased in LE but remained stationary in Fuengirola beach as well as in the surface layer of the EMA stations. Considering the residuals or anomalies, (subtracting the linear trend when existing and the seasonal cycle) we found that air temperature and SST were well correlated both in LE $(r=0.7)$ and in Fuengirola $(r=0.6)$. This correlation increases if the SST and air temperature over the western Mediterranean (Figure 6) is considered.

[49] Béthoux et al. [1998] reported warming trends for the temperature and salinity of deep and intermediate waters in the western Mediterranean and related them to an increase in the radiative forcing caused by global warming. These authors acknowledged that trend estimates for the intermediate waters were less accurate than those for the deep ones because of their larger spatial and temporal variability. Leaman and Schott [1991] and Rholing and Bryden [1992] suggested that the warming of WMDW could be caused by the salinity increase of LIW originated by the damming of the main rivers that drain into the levantine basin. Krahmann and Schott [1998] studied the evolution of temperature and salinity in the western Mediterranean both in the upper layer $(0-70 \mathrm{~m})$ and in the intermediate one $(275-475 \mathrm{~m})$. These authors found that the upper layer temperature remained stationary for the period 1960-1995 while the salinity increased at a rate of $0.13 \mathrm{yr}^{-1}$. The temperature and salinity of the intermediate layer had no variations during this period. Coinciding with previous works, these authors reported an important increase of the NAO index from the mid-1960s. They also reported a decrease in the precipitation rate in the western Mediterranean associated to the NAO positive trend. The two main rivers draining into the northwestern Mediterranean are the Ebro river, in the Spanish coast, and the Rhone in France. Discharges from the Rhone remained constant during the period analyzed while the Ebro discharges suffered an important reduction. According to Krahmann and Schott [1998], the salinity increase of the surface layer could be caused by the precipitation decrease and the reduction of the Ebro river discharges. Considering that, according to these authors, the intermediate waters had not changed their TS properties and the upper layer temperature had not increased, they suggested that the upper layer salinity increase was the responsible for the WMDW warming.

[50] We have detected some discrepancies between results of Krahmann and Schott [1998] and our own data 


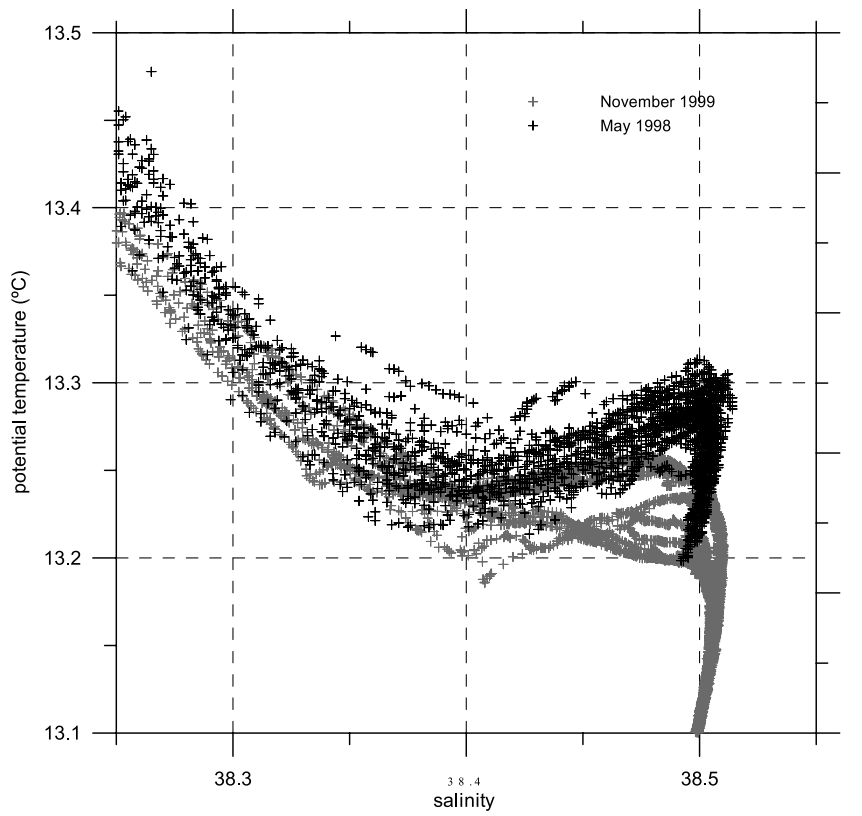

Figure 7. Dark crosses are the $\theta S$ values for 35 profiles obtained in May 1998 within a rectangle extending from $4.5^{\circ}$ to $4^{\circ} \mathrm{W}$ and from $36^{\circ}$ to $36.5^{\circ} \mathrm{N}$. Light crosses are the $\theta S$ values for four repetitions of a hydrographic section carried out in November 1999 at $4.5^{\circ} \mathrm{W}$ and from $36^{\circ}$ to $36.5^{\circ} \mathrm{N}$.

set. DYF time series show a salinity increase at $200 \mathrm{~m}$, not far from the LIW core $(275 \mathrm{~m})$, while the temperature remained constant. On the other hand, no salinity trends have been detected in the surface layer of DYF station. A possible explanation for these discrepancies is that there could be spatial gradients in the sea surface trends that were not taken into account by their spatial average. DYF station should be more influenced by the Rhone river discharges which remained unchanged for the period analyzed by Krahmann and Schott [1998]. These salinity trends should be observed in LE station, closer to the Ebro river, but unfortunately there are no salinity data available in this station. For the discrepancy in the salinity trends for the LIW, a possible explanation could be the different time coverage. According to Krahmann and Schott [1998, Figure 2], around 10 or so monthly averages were available in periods of 5 years, while 12 monthly values per year were obtained in DYF time series. Another factor to be considered is that we have analyzed the period 1991-2001 in DYF station while their time series extended to 1995. As pointed out by these authors, changes in the eastern Mediterranean during the last years could have some influence in the LIW after 1995. More recently, Rixen et al. [2005] reported intense temperature and salinity trends in the intermediate layer $(150-600 \mathrm{~m})$ in the western Mediterranean. Possible reasons for these discrepancies with results of Krahmann and Schott [1998] are the different data set and area considered and the different definition of the intermediate layer. To gather more indications about a possible change in the salinity of the LIW, we have collected all the $\theta S$ profiles from two cruises carried out in the northern sector of the Alboran Sea in May 1998 and
November 1999. Figure 7 shows that the LIW core is clearly visible in almost all the profiles and salinity is clearly over 38.5. Katz [1972] reported a salinity of 38.475 for the LIW in the Alboran Sea in 1970. Gascard and Richez [1985] found that the LIW core in the Alboran Sea could exceptionally reach the value 38.515 , but on the average the maximum of salinity was lower than 38.5 and distributed around the value 38.497. Parrilla et al. [1986] found a value of 38.486 for the LIW salinity. We have found that the mean value of the salinity maximum was 38.506 in May 1998 and 38.507 in November 1999, higher than those previously reported.

[51] Another important difference is that Rixen et al. [2005] reported an intense temperature trend for the upper layer from the mid-1980s. These authors also reported a positive trend of the surface heat fluxes in the northwestern Mediterranean. Our own data set shows intense warming trends in the surface layer, down to $80 \mathrm{~m}$ in LE, down to $50 \mathrm{~m}$ in DYF and at the sea surface in EBA.

[52] Each of our time series provides information about the time evolution of temperature, salinity and heat content at a single location or a reduced area of the western Mediterranean. In the case of DYF station, the upper layer warming could be caused by lateral mixing or advection, vertical mixing or advection with the layer below or changes in the heat exchange through the sea surface. We have shown that the influence of the LIW is felt in this area from $90 \mathrm{~m}$ depth and the core of this water mass is located on the average at $275 \mathrm{~m}$, not far from the upper layer. If the LIW had not increased its temperature during the 1990s we could discard the vertical mixing or advection as the cause of the upper layer warming. The data set analyzed in this work shows no temperature trends at $200 \mathrm{~m}$, neither do time series of temperature for the intermediate layer of the northwestern Mediterranean in Krahmann and Schott [1998]. Contrary to this, Rixen et al. [2005] reported an important warming of the intermediate layer in the western Mediterranean. Regardless the already mentioned differences in the data sets analyzed by these different works, we believe that these discrepancies do not allow us to discard completely the influence of the intermediate layer through vertical mixing or advection on the upper layer warming in the DYF station area. In a similar way, we cannot discard the influence of a possible LIW salinity and temperature increase on the warming of WMDW. LIW flows to the south along the continental slope at a depth ranging from 200 to $600 \mathrm{~m}$. LE station is located over a bottom depth of $85 \mathrm{~m}$ in a coastal area far from the continental slope. For this reason we could accept that the intense warming from the mid-1970s observed in this station is not caused by vertical mixing or advection. This fact suggests that the upper layer warming cannot be explained only on the basis of changes imported from the eastern Mediterranean [CIESM Initiative Group, 2002]. This would also be supported by the air temperature warming and the heat flux increase in the northwestern Mediterranean reported by Rixen et al. [2005]. Nevertheless, we have to admit that single point time series do not allow us to conclude. We cannot compute time series of the different terms involved in the heat balance of a certain water layer. Our results in the Balearic channels offer a good example of the role of advection in the local time variability of 
temperature. The 1995-1996 and 1999-2000 winters have been identified in this work as cold ones and they are followed by an increase of the volume of WIW in the Balearic channels (consequently a decrease of the intermediate layer temperature) and a decrease of temperature in EMU stations (lower than $13^{\circ} \mathrm{C}$ ) during the following spring and summer.

[53] The same limitations outlined above stand for the interpretation of results in the EMA area. The upper layer of the Alboran Sea is filled by AW recently advected from the Atlantic through the Strait of Gibraltar. Air temperature in Fuengirola beach has warmed at a similar rate to those found for LE station and for the western Mediterranean. Nevertheless the sea surface, with a clear Atlantic character (salinity $\sim 36.5$ ) has not increased its temperature during the 1990s. Mediterranean waters are found below the AW layer. The thickness of the Atlantic layer decreases to the east and to the north of Cape Pino. Therefore the Mediterranean waters are closer to the sea surface as we move eastward. Intense warming trends are detected in the deep layers of the continental shelf, coinciding with the presence of Mediterranean waters. Warming trends affect to shallower waters at the eastern stations (Málaga and Vélez) than at the more Atlantic station of Cape Pino. This suggests that the AW advection could play an important role in the heat balance of this area. The influence of LIW in this area is not felt in the upper $250 \mathrm{~m}$.

[54] The data set analyzed shows the warming of the upper layer in DYF station, LE station (not influenced by LIW), at the sea surface of EBA station and in the Mediterranean waters below the AW in the EMA region. The air temperature warming trends since the mid-1970s in the western Mediterranean, the positive trend of the NAO index and the increase of heat fluxes in the northwestern Mediterranean recently reported by Rixen et al. [2005] suggest that there has been a warming of the upper layer of the western Mediterranean caused by an increase of the radiative forcing during the 1990s [Béthoux et al., 1998]. Nevertheless we have to admit that our data set does not allow us to conclude about the role of the LIW warming and its salinity increase. Time series at selected locations allow us to follow the time evolution of water masses characteristics, but do not permit the estimation of the different terms involved in the heat balance equation. Therefore we cannot be sure about the role played by lateral and vertical mixing and advection and cannot completely discard the influence of the LIW on the upper layer warming. Another question that has not been clarified is whether or not the LIW has changed its TS properties during the last part of the 20th century. The data set analyzed in this work has severe limitations as it is limited to the 1990s in most of the cases, but it suggests that the salinity of the LIW has increased during this decade while the temperature remained stationary. This is partly contradictory with Rixen et al.'s [2005] results who reported changes in both temperature and salinity from 1950 to 2000 (including the last decade of 20th century) and completely contradictory with Krahmann and Schott [1998] who reported no variations in the LIW temperature and salinity. All these results do not allow us to make conclusive statements but they suggest that changes in the atmospheric conditions and in the upper layer of the western Mediterranean have occurred during the 1990s decade. Once again, we have to admit that the changes observed during the last decade of the 20th century in the WMED upper layer and the mechanisms proposed for their explanation cannot be extrapolated to explain those observed for the second half of the 20th century and the WMDW warming and our results have to be considered with caution. To finalize we would like to remark the importance of continuing the monitoring of the Mediterranean water masses and of the coastal areas in order to improve our knowledge about the processes and changes undergoing in this area of the world ocean.

[55] Acknowledgments. Projects Ecomálaga, Ecobaleares, Ecomurcia, and CIRBAL are supported by the Instituto Español de Oceanografía. L'Estartit station is supported by the Institut de Ciencies del Mar (ICM, CSIC). Hydrological data from Dyfamed project were obtained from the project Web site (http://www.obs-vlfr.fr/sodyf/home.htm). SST and air temperature were obtained from the National Centre for Environmental Protection/Reanalysis project Web page (http://www.cdc.noaa.gov). We used the Jones et al. [1997] monthly mean NAO index from the Climatic Research Unit (University of East Anglia) Web site (http://www.cru.uea.ac. uk/tiempo/floor2/data/nao.htm). The May 1998 MATER-I cruise was carried out in the frame of the project MTPII-MATER: MAS3-CT960051, supported by the European Union.

\section{References}

Béthoux, J. P., and B. Gentili (1996), The Mediterranean Sea, coastal and deep-sea signatures of climatic and environmental changes, J. Mar. Syst., 7, 383-394

Béthoux, J. P., B. Gentili, J. Raunet, and D. Tailliez (1990), Warming trends in the Western Mediterranean Deep Water, Nature, 347, 660-662.

Béthoux, J. P., B. Gentili, and D. Tailliez (1998), Warming and freshwater budget change in the Mediterranean since the 1940 s, their possible relation to the greenhouse effect, Geophys. Res. Lett., 25, 1023-1026.

Box, E. P., G. M. Jenkins, and G. C. Reinsel (1994), Time Series Analysis: Forecasting and Control, 3rd ed., 598 pp., Prentice-Hall, Upper Saddle River, N. J.

Cano, N., and J. Gil (1984), Campaña Hidrológica Alboran 78, Bol. Inst. Esp. Oceanogr., 1, 114-125.

Chelton, D. B. (1983), Effects of sampling errors in statistical estimation, Deep Sea Res., Part A, 30, 1083-1103.

CIESM (2000), The eastern Mediterranean climatic transient, its origin and impact on the ecosystem, CIESM Workshop Ser. 10, edited by F. Briand, 86 pp., Monaco.

CIESM Initiative Group (2002), Long-term sustained observing system for climatic variability studies in the Mediterranean, paper presented at the Third EuroGOOS Conference, Athens.

Emery, W. J., and R. E. Thomson (1998), Data Analysis Methods in Physical Oceanography, 634 pp., Elsevier, New York.

Fuda, J. L., G. Etipope, C. Millot, P. Favali, M. Calcara, G. Smriglio, and E. Boschi (2002), Warming, salting and origin of the Tyrrhenian Deep Water, Geophys. Res. Lett., 29(19), 1898, doi:10.1029/2001GL014072. García-Górriz, E., and M. E. Carr (2001), Physical control of phytoplankton distribution in the Alborán Sea: A numerical and satellite approach, J. Geophys. Res., 106, 16,795-16,805.

Gascard, J. C., and C. Richez (1985), Water masses and circulation in the western Alboran Sea and in the Strait of Gibraltar, Prog. Oceanogr., 15, $157-216$

Hurrell, J. W. (1995), Decadal trends in the North Atlantic Oscillation: Regional temperatures and precipitation, Science, 269, 676-679.

IFREMER (1997), Mediterranean Hydrological Atlas [CD-ROM], Issyles-Moulineaux, France.

Intergovernmental Panel on Climate Change (2001), Climate Change 2001: The Scientific Basis. Contribution of Working Group I to the Third Assessment Report of the IPCC, edited by J. T. Houghton et al., 944 pp., Cambridge Univ. Press, New York.

Jenkins, G. M., and D. G. Watts (1968), Spectral Analysis and Its Applications, 522 pp., Holden-Day, Boca Raton, Fla.

Jones, P. D., T. Jonsson, and D. Wheeler (1997), Extension using early instrumental pressure observations from Gibraltar and SW Iceland to the North Atlantic Oscillation, Int. J. Climatol., 17, 1433-1450.

Katz, E. J. (1972), The Levantine Intermediate water between the Strait of Sicily and the Strait of Gibraltar, Deep Sea Res., 19, 507-520.

Klein, B., W. Roether, B. B. Manca, D. Bregant, V. Beitzel, V. Kovacevic, and A. Luchetta (1999), The large deep water transient in the eastern Mediterranean, Deep Sea Res., Part I, 46, 371-414. 
Krahmann, G., and F. Schott (1998), Long-term increase in western Mediterranean salinities and temperatures: Anthropogenic and climatic sources, Geophys. Res. Lett., 25, 4209-4212.

Lascaratos, A., W. Roether, K. Nitis, and B. Klein (1999), Recent changes in deep water formation and spreading in the eastern Mediterranean Sea: A review, Prog. Oceanogr., 44, 5-36.

Leaman, K. D., and F. A. Schott (1991), Hydrographic structure of the convection regime in the Gulf of Lions: Winter 1987, J. Phys. Oceanogr., $21,575-598$

Lenschow, D. H., and B. B. Stankov (1986), Length scales in the convective boundary layer, J. Atmos. Sci., 43, 1198-1209.

Levitus, S. (1989), Interpentadal variability of temperature and salinity at intermediate depths of the North Atlantic Ocean, 1970-1974 versus 1955-1959, J. Geophys. Res., 94, 6091-6131.

Levitus, S., I. Antonov, J. Wang, T. L. Delworth, K. W. Dixon, and A. J. Broccoli (2001), Anthropogenic warming of the Earth climate system, Science, 292, 267-270.

Lewis, E. L. (1980), The practical salinity scale 1978 and its antecedents, IEEE J. Oceanic Eng., 5, 3-8.

Millot, C. (1999), Circulation in the western Mediterranean Sea, J. Mar. Syst., 20, 423-442.

Parrilla, G., and T. H. Kinder (1987), Oceanografía física del Mar de Alborán, Bol. Inst. Esp. Oceanogr., 4, 133-166.

Parrilla, G., T. H. Kinder, and R. H. Preller (1986), Deep and Intermediate Mediterranean water in the western Alboran Sea, Deep Sea Res., 33, 5588.

Pinardi, N., G. Korres, A. Lascaratos, V. Roussenov, and E. Stanev (1997), Numerical simulation of the interannual variability of the Mediterranean Sea upper ocean circulation, Geophys. Res. Lett., 24, 425-428.

Pinot, J.-M., J. L. López-Jurado, and M. Riera (2002), The Canales experiment (1996-98): Interannual, seasonal and mesoscale variability of the circulation in the Balearic channels, Prog. Oceanogr., 55, 335-370.

Rholing, E. J., and H. L. Bryden (1992), Man-induced salinity and temperature increases in Western Mediterranean Deep Water, J. Geophys Res., 97, 11,191-11,198.

Rixen, M., et al. (2005), The Western Mediterranean Deep Water: A proxy for climate change, Geophys. Res. Lett., 32, L12608, doi:10.1029/ 2005GL022702.

Roether, W., B. B. Manca, B. Klein, D. Bregan, D. Georgopoulos, V. Beitzel, V. Kovacevic, and A. Luchetta (1996), Recent changes in the eastern Mediterranean deep waters, Science, 271, 333-335.

Salat, J., and A. Cruzado (1981), Masses d'eau dans La Mediterranée occidentale: Mer Catalane at eaux adjacentes, Rapp. Comm. Int. Mer Medit., 27, 201-209.
Salat, J., and J. Font (1987), Water mass structure near and offshore the catalan coast during the winter of 1982 and 1983, Ann. Geophys., 5, $49-54$.

Salat, J., and J. Pascual (2002), The oceanographic and meteorological station at L'Estartit (NW Mediterranean), in tracking long-term hydrological change in the Mediterranean sea, CIESM Workshop Ser. 16, edited by F. Briand, 134 pp., Monaco.

Send, U., J. Font, G. Krahmann, C. Millot, M. Rhein, and J. Tintoré (1999), Recent advances in observing the physical oceanography of the western Mediterranean Sea, Prog. Oceanogr., 44, 37-64.

Theocaris, A., K. Nittis, H. Kontoyiannis, E. Papageorgiou, and E. Balopoulos (1999), Climatic changes in the Aegean Sea influence the eastern Mediterranean transient, Geophys. Res. Lett., 26, 1617-1620.

Thiebaux, H. J., and M. A. Pedder (1987), Spatial Objective Analysis: With Applications in Atmosphere Science, 298 pp., Elsevier, New York.

Tintoré, J., P. E. La Violette, I. Bladé, and A. Cruzado (1988), A study of an intense density front in the eastern Alborán Sea: The Almería-Orán front, J. Phys. Oceanogr., 18, 1384-1397.

Tsimplis, M. N., and T. Baker (2000), Sea level drop in the Mediterranean Sea: An indicator of deep water salinity and temperature changes?, Geophys. Res. Lett., 27, 1731-1734.

Vargas-Yáñez, M., T. Ramírez, D. Cortés, M. Sebastián, and F. Plaza (2002), Warming trends in the continental shelf of Málaga Bay (Alborán Sea), Geophys. Res. Lett., 29(22), 2082, doi:10.1029/2002GL015306.

Vargas-Yáñez, M., et al. (2005), Proyecto Ecomálaga 1992-2001. Part I: Oceanografía física, Inf. Tecn. Inst. Esp. Oceanogr., 183, 1-73.

Xoplaki, E., J. F. González-Rouco, J. Luterbaucher, and H. Wanner (2003), Mediterranean summer air temperature variability and its connection to the large-scale atmospheric circulation and SSTs, Clim. Dyn., 20, $723-739$

D. Cortés, T. Ramírez, and M. Vargas-Yáñez, Instituto Español de Oceanografía, Centro Oceanográfico de Málaga, E-29640 Málaga, Spain. (manolo.vargas@ma.ieo.es)

J. Pascual and J. Salat, Institut de Ciencies del Mar, CSIC, E-08003 Barcelona, Spain.

J. L. López-Jurado and M. Luz Fernández de Puelles, Instituto Español de Oceanografía, Centro Oceanográfico de Baleares, Muelle de Poniente s/n, E-07080 Palma de Mallorca, Spain.

I. Franco, Instituto Español de Oceanografía, Centro Oceanográfico de Murcia, c/Magallanes, no. 2, E-30740 San Pedro del Pinatar (Murcia), Spain. 